\title{
Equality, Equity and Incentives: An Experiment ${ }^{\#}$
}

\author{
Loukas Balafoutas \\ Department of Economics, University of Innsbruck \\ Martin G. Kocher \\ School of Economics, University of East Anglia \\ Louis Putterman* \\ Department of Economics, Brown University \\ Matthias Sutter \\ Department of Economics, University of Innsbruck, \\ Department of Economics, Gothenburg University \\ IZA Bonn
}

This version: 09/16/2010

\begin{abstract}
We devise a new experimental game by nesting a voluntary contributions mechanism in a broader spectrum of incentive schemes. With it, we study tensions between egalitarianism, equity concerns, self-interest, and the need for incentives. In a $2 \times 2$ design, subjects either vote on or exogenously encounter incentive settings while assigned unequal incomes that are either task-determined or random. We find subjects' voting to be mainly self-interested but also influenced by egalitarian and equity concerns, which sometimes cut in opposite directions. Contributions, which seem mainly determined by boundedly rational responses to incentives, are influenced by egalitarian, equity and strategic considerations.
\end{abstract}

JEL Codes: C91, C92, D31, D63, H41

Keywords: equality, efficiency, voluntary contribution mechanism, incentives, experiment

\footnotetext{
\# We thank Dirk Engelmann, Marc Isaac and participants at the 2009 Economic Science Association Meetings in Fairfax, Virginia, the 2010 American Economic Association Meetings in Atlanta, and the 2010 European Economic Association Conference in Glasgow as well as seminar participants at GATE Lyon and the University of Erlangen-Nuremberg for helpful comments and suggestions. Financial support from the University of Munich (from the excellence initiative) and the Tyrolean Science Foundation is gratefully acknowledged. The usual disclaimer applies.

* Corresponding author's address: Department of Economics, Box B, Brown University, Providence, RI 02912 USA. Louis_Putterman@brown.edu.
} 


\section{Equality, Equity and Incentives: An Experiment}

Societies and organizations experience conflicts between desires to attend to the needs of their weaker members, the necessity of providing incentives for generating output, and concerns that reward for effort and contribution of resources be fairly assigned. When weighing these concerns of altruism, incentives and fairness, individuals also consider their self-interest, which is likely to be aligned with some but not all of these factors. At the macro level, the trade-offs in question are navigated, for instance, by determining levels of provision of social benefits and the extent and progressivity of taxation (Okun, 1975; Piketty, 1995; Benabou, 2000). At the micro level, they play out in the negotiation of responsibilities and sharing of consumption in households (Lundberg and Pollak, 1996), and in determination of how differentiated rewards are in organizations (Lazear, 1989; Holmstrom and Milgrom, 1994; Irlenbusch and Ruchala, 2008).

In a business enterprise, rewards tend to be differentiated partly to induce individuals to exert greater effort and partly because each contributor to the team effort has the power to exit if paid less than her best outside option, which may vary from one employee to another. Yet there are also numerous constraints on differentiation of reward. Firm-specific human capital drives a wedge between an employee's marginal value to her employer and the outside value of her current skill set, generating a quasirent the distribution of which is subject to managerial discretion (Williamson et al., 1975). To reduce the danger of invidious comparisons, firms pay workers with similar job descriptions and seniority similar amounts when indications of differences in productivity are not easily verifiable (Baker et al., 1988). In some environments, there may be social or cultural constraints on the maximum gaps between employees at different levels, which may help to explain why the pay differential between top managers and non-managerial employees varies considerably among countries (Abowd and Bognanno, 1995). Finally, many companies implement profit-sharing arrangements partly to encourage helping behaviors among their employees (Kruse, 1992; Bhargava, 1994; Che and Yoo, 2001). 
We study what is perhaps the most fundamental conflict in economic decisionmaking, i.e. the trade-off between equality, equity and incentives, in a stylized experimental environment that reflects the main elements of the problem relevant to both firm and society levels. The paper proposes a new experimental setup that captures this trade-off in a general and transparent way by nesting the standard linear voluntary contributions mechanism (VCM) or public goods game (see Ledyard, 1995, for an early overview, and Zelmer, 2003, for a meta-study) in a more universal but straightforward incentive framework. More specifically, in our experiment a subject is paired with two others and makes a series of fifteen decisions on how much of an endowment of tokens to contribute to a group project and how much to retain as private income. Contributions to the group project are scaled up, mimicking a team production opportunity with a productivity advantage over a private one. What makes our setup new compared to the existing literature and what allows studying the trade-offs mentioned above explicitly is the combination of two features. First, the three group members have unequal endowments ${ }^{1}$ and, second, the money generated by the team can be (i) divided up equally, (ii) in proportion to amounts contributed, or (iii) by any combination of the equal and the proportional distribution rules. With equal distribution, we have a division scheme that provides no incentive for a maximizer of private earnings to contribute but that would render earnings fully equal with at least some gain to all, were all to cooperate completely. With division of team output by contributions, in contrast, there is a straightforward incentive for each to contribute their entire endowment, but earnings are highly unequal. In our experiment, we make the scaling factor of the public good large enough so that over a considerable range of intermediate division settings incentives to contribute remain strong, yet earnings are somewhat equalized, potentially pleasing some and displeasing other group members.

We study contribution responses to varying division parameters in four conditions constituting a $2 \times 2$ factorial experimental design. In two treatments, we allow subjects to determine the setting of the division parameter by majority vote, while in two others the

\footnotetext{
${ }^{1}$ There are several examples of public goods games in the literature that implement unequal endowments: e.g. Chan et al. (1996, 1999), van Dijk et al. (2002), Cherry et al. (2005), Buckley and Croson (2006), and Sadrieh and Verbon (2006). None of them studies the trade-off between incentives and equality.
} 
parameter is set exogenously, tracking the settings of the voting groups so that we can examine the response of contributions to changes in incentives free of strategic motivation to influence voting. The other dimension of variation that we study concerns the origin of the inequality of endowments. We implement two treatments in which unequal endowments are assigned randomly and two in which the endowments are earned by performance on a task (a quiz) that may create feelings of entitlement over the endowment (see, for instance, Hoffman and Spitzer, 1985, Gächter and Riedl, 2005). This allows us to investigate whether voting and responses to incentives are influenced by differing perspectives regarding the fairness of the inequalities within the group.

For treatments in which the division parameter is determined by voting, our setup is predicted to foster a struggle in which selfish low and selfish high endowment subjects attempt to influence the votes of pivotal middle endowment subjects towards their opposing interests. Middle endowment subjects should be indifferent over a wide range of parameter values unless they have preferences over equality or fairness, or if high or low endowment subjects succeed in credibly signaling that their willingness to contribute depends on the parameter in a manner pertinent to middle endowment subjects' selfinterest. Observations with the parameter exogenous permit testing of whether seemingly strategic behaviors in the voting treatments are in fact strategically motivated. And if earned endowments confer entitlement, pro-egalitarian middle endowment subjects will display less concern with equality in the quiz treatment. High and low endowment subjects' contribution decisions may also be influenced by preferences for equality, which may likewise be lessened by entitlement concern when present, since earned inequalities would cause equality and equity to cut in opposing directions, in our setup.

Our experiment provides a number of results. First, subjects respond to the strength of incentives in a roughly continuous fashion, rather than jumping from zero contributions when their marginal return for contributing is below unity to full contributions when it exceeds that threshold, as standard theory would predict. This is true of subjects in each endowment class, and thus appears to stem from bounded rationality rather than from concerns about equality or inequality. Second, high and low endowment subjects' votes are largely predictable from self-interest, with the former mostly favoring payment proportionate to contributions and the latter favoring more 
equal payment. Third, subjects' votes appear to be sophisticated, taking into account the impacts of the distribution parameter on contributions as observed in their groups - that is, they respond to others' responses to incentives in a manner that is selfishly rational on the margin. Fourth, subjects' contributions are influenced by strategic considerations: low endowment subjects contribute more at marginal returns below one when the division is determined by vote, presumably to signal willingness to cooperate despite low incentive. High endowment subjects influence groups' choices of the division parameter by withholding contributions when it is relatively low even though contributing the full endowment maximizes their immediate payoff.

Despite the strong role of self-interest suggested by these findings, our results also include evidence of concerns over inequality and fairness. First, both high and middle endowment subjects sometimes vote for redistribution, and there is evidence that votes are significantly preference-based, with female subjects and those obtaining more cooperative scores in a Ring Test (see Offerman et al., 1996, for an application in economics) selecting significantly more equal parameters. The same subjects also contribute more unconditionally and are less responsive to incentive changes. Second, subjects display greater preference for equality when inequalities are arbitrary than when they are earned by task performance, since low and high endowment subjects are observed to vote for more equality following an otherwise identical history if endowments were not earned.

The remainder of the paper is organized as follows: The following section provides a short overview of the related literature. Section 2 describes our experimental design and our theoretical predictions in greater detail. In Section 3, our results are represented in several analytical steps, and section 4 concludes the paper.

\section{Literature}

The economics literature on inequality ranges from the philosophical and theoretical (Sen, 1997) to work on measurement (Shorrocks, 1983), relationship to economic growth (Galor and Zeira, 1993; Persson and Tabellini, 1994), and political economy (Piketty, 1995; Bénabou, 2000; Bénabou and Tirole, 2006). While hypothetically any desired income distribution can be achieved without efficiency loss by 
a suitable lump-sum transfer of assets, and while opportunities to promote both equity and efficiency occur in some contexts, trade-offs between the need for incentives that reward potentially unequal contributions, and the desire to avoid inequalities and the associated envy, social divisions, and perceptions of injustice, are a ubiquitous fact of economic life.

Disinterested concern with inequality is not always fully separable from selfinterest. The poor and middle income may favor redistribution out of entirely selfish motives (Meltzer and Richard, 1981), and some redistribution may also be favored by the rich out of enlightened self-interest (Grossman, 1995). Nevertheless, models that include preferences to reduce inequality as an end in itself have had success in explaining some observations that appear to be behavioral anomalies from the viewpoint of standard theory. In a much-cited paper, Fehr and Schmidt (1999) propose a model in which individuals get utility from their own income, may get disutility from earning less than others (disadvantageous inequality), and may also get disutility from earning more than others (advantageous inequality), with the weight on advantageous inequality constrained to be no larger than that on disadvantageous inequality. This can explain, among other things, the common rejection of positive but low offers in the ultimatum game (Güth et al., 1982; Camerer and Thaler, 1995). However, subjects are sometimes willing to sacrifice at least small amounts to give large benefits to advantaged others, which Charness and Rabin (2002) see as illustrating a positive weight placed on aggregate social welfare. ${ }^{2}$

At the level of the society, progressive taxation and distribution of welfare benefits are often rhetorically asserted to reflect shared social values, although their selection by electorates is at least in part a natural outgrowth of the right-skewedness of market income distributions. Experiments in which subjects choose among different

\footnotetext{
${ }^{2}$ In their appendix, Charness and Rabin present a more elaborate utility function with a social welfare component that can put varying weights on both aggregate earnings and the earnings of the lowest earner. Since it is difficult to distinguish between inequality aversion and concern for the least well off (the Rawlsian motive) in our experimental design, we will consider the motive for redistributing to the poorest subject to be the first although it could as easily be the second. Considerations of reciprocity, discussed in Charness and Rabin and other papers on other-regarding preferences, will be referred to when explaining cooperation in the VCM but are of second-order importance to our focus on distributive choice.
} 
income distributions for hypothetical societies without direct payoff consequences (Amiel et al., 1999, Johanssen-Stenman et al., 2002) suggest a preference for more equal distributions, and experiments in which similar decisions have a direct payoff consequence to the chooser (Ackert, et al., 2007; Beckman et al., 2004; Schmidt et al., 2009) also show some willingness to pay to achieve greater equality via taxation.

Concerns for fairness sometimes overlap but at other times pull against desires for equality or concern for the least well off. Experimental economists including Hoffman and Spitzer (1985) and Burrows and Loomes (1994) find that subjects place less weight on equality per se when unequal incomes are perceived to have been earned, and Fong (2001), Alesina and Angeletos (2005) and others provide evidence that support for redistribution depends on perceptions of fairness. ${ }^{3}$ In their laboratory experiment on redistributive taxation, Durante and Putterman (2009) find that subjects desire significantly less redistribution when differences are earned by performance on a quiz or game of skill, although the difference is considerably greater among male than among female subjects.

The literature on incentives in organizations includes among its themes the idea that there must be at least potential inequality of earnings (members of a team cannot simply divide their net product by fixed shares) if efficient effort levels are to be elicited (Alchian and Demsetz, 1972; Holmström, 1982; Holmström and Milgrom, 1994). However, inducing maximum competition among team members might mean forgoing important benefits from helping behaviors and mutual monitoring, so that basing some pay on group rather than individual performance may be a more efficient approach (Aoki, 1984; Itoh, 1992). In his seminal paper on gift exchange in the employment relationship, Akerlof (1982) hypothesized that an employer might avoid differentiating pay among similar workers as a form of generosity that more capable workers would reward with greater effort.

The mixing of equal pay and pay-for-effort used in the experiment that follows was first used in a model of cooperatives by Sen (1966). Sen showed that with diminishing returns and thus a decreasing marginal product of labor, payment strictly

\footnotetext{
${ }^{3}$ There is also an experimental literature on competing fairness ideals; see, for example, Cappelen et al. (2010).
} 
proportional to contribution would induce socially excessive effort. Hence, introducing a degree of equalization served as an optimal corrective. ${ }^{4}$ Sen's analysis also showed that complete equality of distribution would generate a low effort equilibrium unless the team members' preferences towards one another were highly altruistic.

The undermining of incentives in a team by egalitarian output sharing à la Sen (1966) or Holmström (1982) has been studied in the laboratory - most often without recognizing this linkage - in the form of the VCM, which in its simplest form asks $n>2$ subjects to allocate endowments of equal size between a group project having a linear technology with marginal social return $n>R>1$ and private projects with marginal return 1. Since the group members share the group project's output without regard to contribution, each one's marginal private return to contributing is $0<R / n<1$. Hence, the privately optimal choice for each is to engage in the private activity only (Isaac and Walker, 1988; Andreoni, 1988; Ledyard, 1995). While actual experimental results disconfirm the prediction of full free riding, with average initial contributions to the group project clustering around $50 \%$ of endowments, subjects gradually approach a freeriding equilibrium with repetition. Despite important evidence that social preferences such as altruism, warm-glow, and reciprocity (conditional cooperation) explain some contributions (Andreoni, 1989, 1990; Palfrey and Prisbrey, 1997; Anderson et al., 1998; Fischbacher et al., 2001; Croson, 2007; Fischbacher and Gächter, 2010), the decay of contributions over time in the absence of punishment opportunities or other added mechanisms remains the standard finding. In other words, the association of a severe free riding problem with the basic design of the VCM is uncontroversial.

In what follows, we re-conceptualize the VCM as the egalitarian end of an array of incentive schemes in which the return from allocations to the group project grows by steps from $R / n<1$ (the VCM with its free-riding incentives) to $R>1$ (an individually profitable opportunity). The nesting of the VCM in such an array of incentive schemes is

\footnotetext{
${ }^{4}$ The model's excessive effort problem, resulting from the link between pay and labor's average product (APL) when APL > MPL (marginal product of labor), appears unlikely to have existed in actual cooperatives due to imperfect observability of individual effort. More important for present purposes, the problem has no direct counterpart in our experiment because we impose a constant marginal product and thus APL $=$ MPL.
} 
also used in Grosse et al. (2010), but in their model VCM incentives represent a lack of monitoring, not a preference for egalitarian distribution. Whereas Grosse et al.'s subjects face the problem of free-riding incentives if they fail to achieve mutual monitoring or bring in a specialist monitor as suggested by Alchian and Demsetz (1972), subjects in the present paper's endogenous parameter treatments experience or evade free-riding incentives as a function of voting choices potentially influenced by self-interest, egalitarian sentiments, and conceptions of fairness.

\section{Experimental Design and Predictions}

\subsection{Basic setup}

We conducted two sessions of each of four treatments (see Table 1). In each treatment, 36 subjects are randomly assigned to fixed groups of 3 who remain anonymous to one another, in two sessions of 18 subjects each. In each group, one subject has an endowment of 5 tokens, a second an endowment of 10 tokens, and a third an endowment of 15 tokens, with a given subject receiving the same endowment in each of 15 periods of play, a finitely repeated design. In each period, subjects must decide how many tokens to put in the group project, with the remainder being placed in a private account. In a given period, subject $i$ earns

$$
y_{i}=\left(E_{i}-C_{i}\right)+(1-\alpha) R \frac{C}{3}+\alpha \frac{C_{i}}{C} R C=\left(E_{i}-C_{i}\right)+(1-\alpha) R \frac{C}{3}+\alpha R C_{i}
$$

where $E_{i}$ is $i$ 's endowment $(5,10$ or 15$), C_{i}$ is his or her contribution to the group project (an integer), $C=\sum_{j=1}^{3} C_{j}$ is the sum of the three contributions in a given period, $j=l, m$, $h$ represents the low, middle, and high endowment subjects respectively, $1<R<3$ is the scaling factor, and $\alpha((1-\alpha))$ is the share of group output distributed on the basis of contributions (equally). In the experiment, $\alpha \in\{0,0.1,0.2, \ldots, 1\}$, and we set $R=2$, so equation (1) becomes

$$
y_{i}=\left(E_{i}-C_{i}\right)+(1-\alpha) \frac{2}{3} C+\alpha 2 C_{i}
$$


This choice of parameters means that the marginal return from contributing to the group project, $\partial y_{i} / \partial C_{i}$, is less than 1 when $\alpha<0.25$ and greater than 1 when $\alpha>0.25$. If all subjects are strictly self-interested, perfectly rational, and have common knowledge of this, then contributions should be zero and earnings 5, 10 and 15, respectively, when $\alpha=$ $0,0.1$ or 0.2 . Under the same assumptions, contributions should be equal to endowments when $\alpha \geq 0.3$, with earnings out of the fixed total of 60 varying from a relatively equal 17,20 , and 23 when $\alpha=0.3$ to their most unequal values of 10,20 and 30 when $\alpha=1$. This wide scope for equalization without in theory undermining incentives creates a broad space for expression of distributive preferences, distributional conflict, and "posturing" so as to influence voting outcomes.

To be sure, endowments such that the median endowment was below the average would generate a right-skewed earnings distribution more like that commonly observed at the macro political level, and are thus worth investigating in future research. However, the symmetrically distributed endowments in our design make it easier to identify the effects of redistributive preferences and countervailing incentive concerns, since this symmetry causes each group's median voter to have no personal stake in how income is divided, apart from such concerns.

\section{Insert Table 1 around here}

In the Quiz-Vote (henceforth also $\mathbf{Q V}$ ) and Quiz-Exogenous (QE) treatments, subjects first complete a twenty-minute general knowledge quiz before being assigned to the low, middle or high endowment level based on their performance. In $\mathbf{Q E}$, they then proceed to make fifteen contribution decisions, each time with an $\alpha$-value that is exogenous to them being announced at the beginning of the period, and with the decisions and earnings of all subjects being announced at the end of the period. The Random-Exogenous ( $\mathbf{R E}$ ) treatment is like the $\mathbf{Q E}$ treatment except that there is no quiz and the endowment levels are assigned randomly. In the $\mathbf{Q V}$ and Random-Vote (RV) treatments, subjects specify the value of $\alpha$ that they favor at the beginning of each period and are then shown the value selected by the group - the median value among the three 
submitted - before proceeding to make their contribution decisions. ${ }^{5}$ The $\mathbf{R V}$ treatment differs from $\mathbf{Q V}$ but resembles $\mathbf{R E}$ in that there is no quiz and endowments are assigned randomly. To facilitate testing of whether exogeneity of $\alpha$ influences contribution decisions, we match each $\mathbf{R V}$-treatment group to an $\mathbf{R E}$ group and assign the latter the precise sequence of $\alpha$ 's selected by voting in the former, although $\mathbf{R E}$ subjects are not informed that this is what determines $\alpha .{ }^{6}$ Each QE-treatment group is likewise assigned the sequence of $\alpha$ 's determined by the median voter in a counterpart $\mathbf{Q V}$ group. Subjects knew in advance that there would be exactly 15 periods of play, each subject knew that his or her endowment and group composition would not change, and in the $\mathbf{Q V}$ and $\mathbf{Q E}$ treatments subjects knew that their performance on the quiz would determine their endowment.

\subsection{Theoretical predictions}

\subsubsection{Full rationality and self-interest}

Rational payoff-maximizing subjects who know that all are of the same type would select $C_{i}=0$ in all periods in which $\alpha \leq 0.2$ and $C_{i}=E_{i}(=5,10$ or 15$)$ in all periods in which $\alpha \geq 0.3$. Thus, standard economic theory gives our first (non-behavioral) hypothesis:

Hn.1: $C_{i}=0, E_{i}$ as $\alpha \leq 0.25, \alpha \geq 0.25$.

\footnotetext{
${ }^{5}$ The median vote is often used in experiments as a representation of a democratic decision in view of the well-known median-voter theorem in public choice theory, since explicit competition among proposals would be time-consuming. The outcome of a multi-stage competition would also be sensitive to procedural details, and thus we make no claim that the median position represents a majority view in any strict sense. Note that individual votes were not reported to the group, so there was no way to use votes to convey individual preferences.

${ }^{6}$ They were simply told that the relevant $\alpha$-value for a specific period would be announced at its beginning and that it would always come from the set $\{0,0.1,0.2, \ldots, 1\}$. Details are provided in the experimental instructions in Appendix C.
} 
When considering how to vote in the $\mathbf{Q V}$ and $\mathbf{R V}$ treatments, such subjects should likewise assume that $C_{i}=0$ for all $i$ when $\alpha \leq 0.2$ and $C_{i}=E_{i}$ for all $i$ for $\alpha \geq 0.3$. Given this, if it were assumed that subjects simply voted their interest without consideration of how others might vote, low endowment subjects would vote for $\alpha=0.3$, which maximizes their earnings at 17, high endowment subjects would vote for $\alpha=1$, which maximizes their earnings at 30 , and middle endowment subjects would be indifferent between the eight values of $\alpha$ from 0.3 to 1 , since they earn 20, regardless. Assuming that the middle endowment subjects choose randomly among these values, $\alpha$ would thus vary randomly over the 0.3 -to-1 range, and expected incomes would be mid-way between the most and least equal sets reported above, i.e. 13.5, 20 and 26.5. When taking others' expected votes into account, both high and low endowment subjects can reason that the middle endowment subject's voted $\alpha$ - call it $\alpha_{m}-$ will be decisive. A high endowment subject has no reason to favor one value over another in the interval $\alpha_{m} \leq \alpha \leq 1$, but with no way to anticipate what $\alpha_{m}$ will be in a given period, a high endowment voter should always choose the weakly dominant strategy of voting for $\alpha=1$. $^{7}$ The position of the low endowment subject, who would likewise be indifferent among values of $\alpha$ in the interval $0.3 \leq \alpha \leq \alpha_{m}$, is slightly different, because she can safely vote for $\alpha=0,0.1,0.2$ or 0.3 without fear of raising $\alpha$ above her preferred value (0.3). Hypothesis Hn.2 summarizes these considerations.

Hn.2: High endowment subjects always vote for $\alpha=1.0$, middle endowment subjects distribute their votes randomly for $\alpha$-values in the interval from 0.3 to 1.0, and low endowment subjects choose any $\alpha \in[0 ; 0.3]$. Thus, the median vote is always cast by the subject with the middle endowment.

\subsubsection{Heterogeneous (social) preferences}

We consider two forms of social preferences that may cause subjects' behaviors to deviate from what would maximize their own pay-offs. These are (a) inequality aversion, and (b) concerns with equity, or respect for "earned" inequalities. The presence and

\footnotetext{
${ }^{7}$ The trembling hand perfection argument (Selten, 1975) can also be used to motivate an $\alpha_{h}=1$ prediction.
} 
weight placed on each preference may vary among individuals and when present may affect both contribution and voting choices.

With regard to (a), suppose that each subject's utility takes the form modeled by Fehr and Schmidt (1999), as described in Section 1. For our high endowment subjects, only advantageous inequality is of potential concern, for low ones only disadvantageous inequality, and for middle ones, both advantageous and disadvantageous inequalities are potential concerns. If subjects vote on our parameter $\alpha$ assuming that inequality aversion has no first-order effect on contributions, inequality aversion would not alter the vote of a low endowment subject, who in the absence of social preferences already votes for $\alpha \leq$ 0.3 . But both middle and high endowment subjects would vote for lower values of $\alpha$ than otherwise if they are sufficiently inequality averse. Indeed, since no income sacrifice is required of her under these assumptions, a middle endowment subject with any degree of inequality aversion would vote for $\alpha=0.3$, eliminating both most advantageous and most disadvantageous inequality in a single stroke. A high endowment subject, in contrast, incurs a loss of own income to reduce only advantageous inequalities. Hence, assuming similar distributions of inequality aversion in high and middle endowment subjects, we should expect more downward bias in votes for $\alpha$ due to inequality aversion on the parts of middle than of high endowment subjects. ${ }^{8}$

Factor (b), the desire of some subjects that "earned" inequalities not be unfairly eliminated, can be present - in our QV treatment - in the same individuals who are inequality averse, or by itself. If present alone, this equity concern will have no influence on the votes of high endowment subjects (who select $\alpha=1$ in any case), may cause middle-endowment subjects to bias their votes upwards within the $0.3 \leq \alpha \leq 1$ range, and may lead some low-endowment subjects to vote, contrary to their own interest, for $\alpha>$

\footnotetext{
8 A more complete analysis requires considering the possible effects of inequality aversion on contributions. In particular, sufficiently inequality-averse high endowment subjects would contribute to the group project even at low levels of $\alpha$ so as to reduce advantageous inequality, and inequality-averse middle endowment subjects might do so if they assumed that high endowment subjects do. These changes in the relationship between $\alpha$ and contributions could in turn affect voting, but are expected to be of second-order importance only.
} 
0.3. For subjects having both equality and equity preferences, the prediction is one of favoring higher values of $\alpha$ in the $\mathbf{Q V}$ than in the $\mathbf{R V}$ treatment.

Assuming substantial numbers of subjects who are averse to inequalities, averse to equalizing earned inequalities, or both, we make the following behavioral predictions:

Hb.1. Middle and low endowment subjects will on average vote for lower a in the $\boldsymbol{R} \boldsymbol{V}$ than in the $\mathbf{Q V}$ treatment. Some high endowment subjects will vote for $\alpha$ $<1$, and more high endowment subjects will do so, voting for lower values of $\alpha$, in the $\boldsymbol{R} \boldsymbol{V}$ than in the $\mathbf{Q V}$ treatment.

\subsubsection{Strategic considerations}

There are several strategic, i.e. reputational, and preference-based reasons why individuals may choose contributions other than those that are statically payoffmaximizing for them. In the voting treatments subjects may use their choices of $C_{i}$ to signal willingness or unwillingness to contribute at given $\alpha$ in order to influence others' subsequent votes. And if subjects' utilities are interdependent, positive or negative concern for others can influence contributions even in the non-voting treatments, since one's contribution affects one's group-mates earnings whenever $\alpha<1$.

With respect to strategy, high endowment subjects who seek to maximize their payoffs would want, if possible, to influence the middle endowment subjects to vote for higher values of $\alpha$. A behaviorally realistic scenario would be that the high endowment subjects might (except in the last period) reduce $C_{h}$ when $\alpha$ is in the low end of the 0.3-to1 range, even though they incur a cost in short-run earnings, in order to signal their displeasure with the low $\alpha$-value. If there were truly common knowledge of full rationality and of utilities depending on payoffs only, such moves would be pointless, because the subjects could not credibly threaten to hold $C_{h}<15$ in the last period, whereupon setting $C_{h}<15$ in the next-to-last period will also have no effect, and so forth. Realistically, however, subjects may not be sure of others' types, and there may exist subjects with, for example, a "taste for distributive justice" sufficiently strong to willingly incur a payoff loss as a cost for signaling their preference, so $C_{h}<15$ seems a likely possibility when $\alpha$ is low, at least in early periods of the $\mathbf{R V}$ and especially (assuming 
some inequality and inequity aversion) the $\mathbf{Q V}$ treatment. That $C_{h}$ will be lower in treatments with voting than in those without for given values of $\alpha$ that exceed 0.25 but are not too far above 0.3 is our second behavioral prediction for the experiment. ${ }^{9}$

Hb.2. High endowment subjects will contribute less in the voting than in the non-voting treatments when $0.3 \leq \alpha<1$, with contributions that are lower the lower is $\alpha$ and the earlier is the period.

Contrary to the standard theory's prediction that $C_{i}=0$ in all periods in which $\alpha=0$, 0.1 or 0.2 , subjects who favor greater equality either for self-interest or for inequalityaversion reasons may contribute to the group project despite such low values of $\alpha$, in an effort to make equality more palatable and to moderate the equality-efficiency trade-off. Low endowment subjects, especially, are predicted to contribute more of their endowments than others when $\alpha=0,0.1$ or 0.2 and $\alpha$ is determined by vote, since this could reduce the costliness of low $\alpha$ as perceived by other group members thereby leading them to vote for such values in future periods. Inequality-averse middle and high endowment subjects may also contribute when $\alpha=0,0.1$ or 0.2 , especially in the $\mathbf{R V}$ treatment, where inequalities are unearned and contributions may influence subsequent votes. For the same reason, inequality-averse high endowment subjects will engage in no or at least in less strategic withholding of contributions when $0.3 \leq \alpha<1$.

Hb.3. Low endowment subjects and inequality-averse middle and high endowment subjects will contribute positive amounts when $\alpha \leq 0.2$ and $\alpha$ is determined by vote, so as to encourage further votes for lower values of $\alpha$, and the extent of this behavior will be greatest in the $\boldsymbol{R} \boldsymbol{V}$ treatment. Inequalityaverse high endowment subjects will also engage in less strategic withholding of contributions than others with high endowment when $0.3 \leq \alpha<1$.

\footnotetext{
${ }^{9}$ Low endowment subjects could conversely withhold contributions to try to sway the middle endowment subject's vote when $\alpha$ is high.
} 
Note that the tendency of contributions to respond to changes in the marginal incentives continuously rather than with a discrete jump (see Isaac and Walker, 1988, for systematic evidence on this relation) means that the predictions of $\mathrm{Hb} .3$ must be tested carefully, since there can be positive contributions at $\alpha \leq 0.2$ independent of the desire to influence votes.

\subsection{Laboratory protocol}

The computerized experiment was programmed using z-Tree (Fischbacher, 2007). A total of 144 participants (36 for each of the treatments), who were invited by using the software ORSEE (Greiner, 2004), took part in the eight sessions of the experiment (two per treatment), all of them being undergraduate students with different study backgrounds.

Sessions proceeded in the following way: Upon entering the laboratory, participants were randomly assigned to cubicles and provided with written instructions (see Appendix C) for the first part of the experiment, i.e. the Ring-test. ${ }^{10}$ The instructions were read out aloud by the experimenter. Subjects knew that there will be a second part of the experiment and that it will be unrelated to the first part. Upon completion of the first part, the instructions for the second part were handed out and read aloud. Participants were then asked to answer a set of twelve control questions to make sure that the rules of the game had been fully understood. Any incorrect entries were corrected and all remaining questions were clarified before the second part commenced. In the treatments with the quiz, subjects began this part with the trivia questions that, then, determined the endowment of a subject throughout the second part of the experiment. Treatments without the quiz started with the random assignment of endowments. When taking the

\footnotetext{
${ }^{10}$ In this fully incentivized test, subjects have to make binary choices in 24 different allocation tasks (see Appendix D). In each task, a subject has to choose among two alternative ways of allocating money to herself and a recipient. Adding up the 24 decisions yields a total sum of money allocated to oneself ( $x$ amount) and to the recipient ( $y$-amount). From the ratio $(x / y)$ one can calculate a subject's social orientation, indicated by a vector $\theta$, which can then be classified into any of eight categories: individualism, altruism, cooperation, competition, martyrdom, masochism, sadomasochism, and aggression. See Offerman et al. (1996) or Brosig (2002) for further details on the Ring-test.
} 
quiz subjects knew the details of the game to commence after the quiz, and they knew that they were already randomly assigned to a three-person group and that the member with the most correct answers would become the high endowment subject, the member with the second-most correct answers the middle endowment subject, and the member with the fewest correct answers the low endowment subject.

At the end of each period, subjects were informed about all individual contributions within their groups linked to IDs and their own period incomes in tokens as well as the individual period income in tokens of the other two group members. After 15 periods, the experiment ended, subjects filled out a brief questionnaire (from which we extract the gender information used later), and subjects were paid out privately and in cash. Sessions lasted in total for a bit less than two hours, including payment. At the end of each session, the accumulated period profits in tokens were converted into euro at the pre-announced rate. Average earnings were $€ 33.47$ per subject, which breaks down into $€ 5.59$ for part 1 (the Ring test) and $€ 27.88$ for part 2 (the main experiment).

\section{Results}

We first provide a descriptive overview of our results regarding voting (in section 3.1.1) and contributions (section 3.1.2) and then proceed with more detailed regression analyses and non-parametric tests (section 3.2).

\subsection{Descriptive overview of results}

\subsubsection{Voting}

Table 2 provides an overview of some key outcomes by treatment. Beginning with the votes that subjects cast for the distribution parameter $\alpha$, we see that as predicted the preferred $\alpha$ tended to be lower for low than for high endowment subjects, with the average value voted for by middle endowment subjects lying in between. This tendency to vote differently depending on endowment is associated with statistically significant differences, as shown by Kruskal-Wallis tests and pairwise Mann-Whitney U tests (all with $p<0.001$ ). The averages in Table 2 and the corresponding Figure 1 show, in line with our prediction in Hn.2, that low endowment subjects clearly did not always vote for 
$\alpha$ of $0.3, \alpha$ of 0 being in fact their modal choice, and with their average vote for $\alpha$ being a little greater than 0.3 in $\mathbf{Q V}$, and a little less than 0.2 in $\mathbf{R V}$. High endowment subjects sometimes voted for $\alpha<1$, a result more consistent with Hb.1 than with Hn.2. The higher average $\alpha$ voted for by low and high endowment subjects when endowments were determined by quiz than when they are random are consistent with the presence of inequality aversion for random endowments and with a sense of legitimacy of earned inequalities in $\mathbf{Q V}$, as anticipated in Hb.1. Middle subjects' votes, while roughly consistent with voting randomly over the $0.3 \leq \alpha \leq 1$ range especially in the QV treatment, are for higher rather than lower $\alpha$ 's when endowments are random, contrary to $\mathrm{Hb}$.1. The middle subject turned out to be the median voter (sometimes tied with another group member) in $2 / 3$ of all votes in $\mathbf{Q V}$ and in $76.1 \%$ of votes in $\mathbf{R V}$, largely but not entirely in line with hypothesis Hn.2. ${ }^{11}$

\section{Insert Table 2 and Figure 1 around here}

Figure 1 shows the relative frequency of votes for each possible value of $\alpha$. We note both for treatment $\mathbf{Q V}$ and $\mathbf{R V}$ a strong difference between low, median and high endowment subjects. Low endowment subjects vote in both treatments in the majority of cases for $\alpha \leq 0.2$, with the modal choice being $\alpha=0$. In general, low endowment subjects on average cast their vote as if they view inequality that disfavors them as being more acceptable when it is the result of performance (in $\mathbf{Q V}$ ) than pure luck (in $\mathbf{R V}$ ).

\footnotetext{
${ }^{11}$ In other words, Hn.2 is supported with respect to middle endowment subjects being the median voters between $2 / 3$ and $3 / 4$ of the time. This does not contradict the behavioral hypotheses on voting, which also permit the middle endowment subject to be the median voter if tastes for equality or equity are not too strong. However, the behavioral hypotheses can explain some of the departures, for example a low (high) endowment subject with strong sense of equity (preference for equality) could vote for a higher (lower) $\alpha$ than a middle endowment subject who is simply maximizing his income and thus selecting $\alpha$ randomly in the 0.3 to 1.0 range. Ties were most often with high endowment subjects: in 144 out of 360 decisions, the high and middle subjects concurred on the same $\alpha$ (usually 1); in 30 decisions, the high and low endowment subjects concurred; in 21 cases, the middle and low concurred; and in 16 cases, all three concurred.
} 
High endowment subjects have a clear preference for $\alpha=1$ (receiving $87 \%$ of their votes in $\mathbf{Q V}$ and $78 \%$ in $\mathbf{R V})$. However, they cast $11 \%(18 \%)$ of votes in $\mathbf{Q V}(\mathbf{R V})$ in the range $0.3 \leq \alpha \leq 0.9$, supporting $\mathrm{Hb}$.1's prediction both of some high endowment subjects voting for $\alpha<1$ and for more of this in $\mathbf{R V}$ ( $p=0.027, \chi^{2}$-test).

For middle endowment subjects, $\alpha=1$ is also the modal choice, accounting for $43 \%$ (59\%) of votes in QV (RV). This frequency of middle subjects' votes for $\alpha=1$ is at odds with the Hn.2 prediction that they would randomize votes over the 0.3 to 1.0 range (even though than more than $80 \%$ of votes are in this range) and suggests instead a concern with the behavioral and/or strategic sensitivity of contributions to $\alpha$ that we discuss in the next sub-section.

\subsubsection{Contributions}

In Table 2 and in much of our discussion we do not report absolute contribution $C_{i}$ but proportions of endowment contributed, $C_{i} / E_{i}$, which aids comparability across endowment levels. On average, subjects contributed to their group project the large majority of their tokens, ranging from $82.8 \%$ of their endowments in the $\mathbf{Q E}$ treatment to $88.4 \%$ in the $\mathbf{R E}$ treatment. These contribution averages are not far from what would be expected had behaviors adhered to Hn.1, with subjects contributing their full endowments or zero depending on whether $\alpha$ is smaller or larger than 0.25 . Given that we have $\alpha<$ 0.25 in $12.5 \%$ of periods and $\alpha>0.25$ in $87.5 \%$ of periods, $C_{i} / E_{i}$ would have been $87.5 \%$

on average had all subjects behaved as predicted by Hn.1. We will see shortly, however, that actual contributions vary almost continuously as $\alpha$ varies.

The last three rows of Table 2 report average $C_{i} / E_{i}$ separated not by endowment but rather by the range in which the group's median incentive parameter $\alpha$ lies. We report average $C_{i} / E_{i}$ during periods in which $\alpha<0.25$ (VCM incentives), average $C_{i} / E_{i}$ when 0.3 $\leq \alpha \leq 0.6$ (in theory high enough to induce full contributions but possibly inducing lower contributions either due to a continuous response to incentives associated with bounded rationality, or to high contributors' resistance to "unfair" sharing, or both), and lastly average $C_{i} / E_{i}$ during periods in which $0.7 \leq \alpha \leq 1$ (a range of strongest incentives from a behavioral perspective to contribute the entire endowment). For each treatment, the average proportion contributed is substantially above 0 even if $\alpha<0.25$, and it rises as the 
range of $\alpha$ does, demonstrating that contributions respond more smoothly to incentive changes (see also Figure A.1 in Appendix A). In the VCM range $(\alpha<0.25)$ average contributions are far lower in the $\mathbf{Q V}$ and $\mathbf{Q E}$ treatments than in the $\mathbf{R V}$ and $\mathbf{R E}$ treatments, consistent with greater willingness to contribute despite low incentives when inequality is viewed as arbitrary. The difference is more pronounced in the treatments with exogenous endowments (i.e., the QE vs. RE comparison), suggesting that it is not mainly attributable to the desire to influence voting. ${ }^{12}$

\subsection{Regression analyses and further results}

For a more nuanced view of the determinants of voting and of how contributions are affected by the distribution parameter in different treatments and for subjects having different endowments, it is helpful to simultaneously control for several variables using multivariate regressions, although the usual caveats regarding independence of observations need to be kept in mind.

When studying voting and contribution decisions a potential endogeneity bias arises in regressions that study the two types of decisions separately. However, applying a 2SLS/IV strategy is also problematic because the value of $\alpha$ that affects decisions in the contribution stage is determined in the voting stage by a subset of subjects only, namely those voting for the median value. In the following, we therefore discuss separate estimates, first considering the determinants of the contribution choice (in section 3.2.1) and then the determinants of the voting decision (section 3.2.2). We check for potential problems that arise from endogeneity issues by estimating 2SLS models for the relevant sample, but reserve results for an appendix. It is comforting to note that the estimated 2SLS models cannot reject the exogeneity of $\alpha$ as a determinant of contributions at anything approaching conventional levels (see Appendix B). In addition to regression analyses, each of the following sub-sections also reports further non-parametric testing of hypotheses relating to its topic.

\footnotetext{
${ }^{12}$ The overall difference between contributions in the quiz and in the exogenous endowment treatments is highly significant (Mann-Whitney-U-test, $p<0.001$ ). Similar differences appear when comparing $\mathbf{Q V}$ to $\mathbf{R V}$ and $\mathbf{Q E}$ to $\mathbf{R E}$ separately, but the first difference is statistically insignificant while the second is significant at the $5 \%$ level.
} 


\subsubsection{Contribution decisions}

Table 3 shows four regression models attempting to explain the proportion of endowment that subjects contribute as a function of the current value of $\alpha$, its square, dummy variables denoting low and middle endowment subjects (with the high endowment subjects being the reference group), a dummy variable for quiz-determined endowments (Quiz), a dummy for voted (as opposed to exogenous) $\alpha$ (Vote), a period trend term, lagged $C_{i} / E_{i}$, and interactions of the low and middle endowment dummies with $\alpha$, Quiz, and Vote, to allow for the possibility that their effects differ by endowment. Columns (1) and (2) differ with respect to inclusion or not of group fixed effects. The estimates for both specifications show $C_{i} / E_{i}$ to be significantly increasing in $\alpha$, indicating once more that contributions respond in a continuous fashion to $\alpha$, instead of jumping from zero to full endowment at $\alpha=0.25 \cdot{ }^{13}$ Coefficients on $\alpha^{2}$ are negative, suggesting concavity, but not consistently significant. $C_{i} / E_{i}$ does not appear to vary significantly for the two distinguished endowments or their interaction with $\alpha$. The coefficients on the Quiz-dummy are negative and significant, indicating that contributions are significantly smaller when endowments are determined by performance, an effect that seems not to differ by endowment (see the interaction terms). Determination of $\alpha$ by vote affects $C_{i} / E_{i}$ positively, although this effect seems lessened or even reversed for middle endowment subjects. Not surprisingly, there is significant persistence of individual contributions, ceteris paribus. There is no indication of a time trend in contributions.

\section{Insert Table 3 around here}

The regressions in columns (3) and (4) add interaction terms between the treatment dummy variables (Quiz and Vote) and a dummy for observations in which $\alpha<0.8 .{ }^{14}$ The

\footnotetext{
${ }^{13}$ To show this more formally, we estimated Table 3's regressions using an $\alpha \geq 0$.3-dummy variable in place of or in addition to the variables $\alpha$ and $\alpha^{2}$, finding that the fit is superior (judged, for example, by the $\mathrm{R}$-squared and the Akaike information criterion) when using either $\alpha$ and $\alpha^{2}$ or $\alpha$ alone than when using the cut-off dummy.

${ }^{14}$ Interactions between the treatment dummies and the endowment dummies are omitted in column (4).
} 
first of the new interaction terms returns highly significant negative coefficients, indicating that the negative impact of Quiz on proportion contributed was about twice as large when $\alpha$ was low. This suggests that a major reason why quiz-based endowments caused lower contributions is that more subjects found lower, redistributive values of $\alpha$ unacceptable when differences in endowment were "earned." 15 But since the coefficient on Quiz remains significant even when this interaction term is included, protest or resentment of redistribution cannot be the only explanation. The interaction between Vote and low $\alpha$ is insignificant, providing no direct support for the idea that subjects contribute less when there is voting in order to prompt votes for higher values of $\alpha$.

\section{Do low endowment subjects signal that they don't require incentives?}

$\mathrm{Hb} .3$ suggests that in order to encourage others to vote for low values of $\alpha$, low endowment subjects will contribute in spite of weak or absent monetary incentives. We test this hypothesis by investigating whether, for given low values of $\alpha$, low endowment subjects contribute more in a treatment with endogenously chosen $\alpha$ than in a corresponding treatment in which $\alpha$ 's value is set exogenously. Our design allows us to match up each observation for a low endowment subject in treatment RV with a corresponding observation for the unique treatment RE-subject having exactly the same history of values of $\alpha$ up to the same period, and to likewise match each $\mathbf{Q V}$ observation with a unique corresponding observation from the $\mathbf{Q E}$ treatment. We then perform a Wilcoxon-signed-ranks-test of the difference in $C_{i} / E_{i}$ (equivalently $C_{i}$, since we look only at subjects with $E_{i}=5$ ). Because there are relatively few observations for which $\alpha=0,0.1$ or 0.2 , we expand the set of "low $\alpha$ "-observations to include all in which $\alpha \leq 0.5{ }^{16}$ Observations for the final period are excluded, since strategic incentives would be absent when choosing $C_{i}$ at that point.

When the paired observations of both pairs of treatments are pooled, the test finds no significant difference between the contributions in the treatment with voting and those in the treatment with exogenous $\alpha$. However, $\mathrm{Hb} .3$ predicts a stronger effect in the

\footnotetext{
${ }^{15} \mathrm{Hb} .1$ deals with the effect of this judgment on voting, while $\mathrm{Hb} .2$ is consistent with the effect seen for contributions but deals explicitly with high endowment subjects only.

${ }^{16}$ There are a total of 60 cases of $\alpha \leq 0.2$ in the four treatments versus 176 cases of $\alpha \leq 0.5$.
} 
treatments with random endowments, because low endowment subjects in the Quiz treatments might have reservations about "pushing for" lower values of $\alpha$ when endowments are viewed as earned and inequality is accordingly considered more "fair." Therefore, we also test only the paired $\mathbf{R V}$ and $\mathbf{R E}$ observations for subjects with the low endowment. We find that $\mathbf{R V}$ subjects contributed significantly more than $\mathbf{R E}$ subjects at given low values of $\alpha$ (for periods $1-14, p<0.05$ ). Thus, in the two treatments in which a stronger effect is predicted, the data support $\mathrm{Hb} .3$.

Do high endowment subjects signal demands for higher a by withholding contributions in voting treatments?

High endowment subjects may have contributed less when $\alpha$ was low ( 0.3 or just above) than when it was high (1.0 or close to 1.0$)$, partly due to the same behavioral responsiveness to marginal incentives exhibited by other subjects. We can check whether high endowment subjects strategically contributed less at low values of $\alpha$ so as to induce others to vote for higher $\alpha$ by comparing their contribution levels when $\alpha$ was low but still high enough to make full contributions rational, say $0.3 \leq \alpha \leq 0.7$, in treatments with voting and in those without. Hb.2 implies that in this range and especially in early periods, high endowment subjects' contributions will be lower in RV than in RE. The difference will be even stronger for $\mathbf{Q V}$ versus $\mathbf{Q E}$ if subjects feel more entitled to higher earnings when their endowments were attributable to their performance. Contrary to this hypothesis, Wilcoxon matched pair tests find that high endowment subjects contributed more in the two voting than in the two non-voting treatments in given periods and at given values of $\alpha$ in the 0.3 to 0.7 range $(p<0.01)$. Moreover, the difference is entirely attributable to the pair of treatments with quiz-based endowments: contributions by high endowment subjects are higher in $\mathbf{Q V}$ than in $\mathbf{Q E}(p<0.01$; Wilcoxon matched pair test), whereas the contribution difference between $\mathbf{R V}$ and $\mathbf{R E}$ taken alone is not significant. It would appear that high endowment subjects consider low $\alpha$ unfair and thus withhold contributions out of dissatisfaction and not necessarily out of desire to influence future votes. The finding that contributions in the low $\alpha$-range are higher in $\mathbf{Q V}$ than in $\mathbf{Q E}$ might, on the contrary, even be attributable to the high endowment subjects considering 
low $\alpha$-values to be less unfair when they have been chosen democratically than when they are exogenously imposed.

\section{Effects of gender and cooperativeness}

In our theoretical discussion, including that of $\mathrm{Hb} .2$ and $\mathrm{Hb} .3$, we hypothesized that behavior might differ depending on subjects' degrees of inequality aversion, an individual preference parameter. To explore this issue, we investigate the impact of two individual characteristics - gender, and Cooperativeness (Coop), a measure constructed from the Ring-test decisions (see Appendix D for details). Table 4 presents a series of regressions explaining share of endowment contributed using the same explanatory variables as in the regressions of Table 3 but adding a Female dummy and/or the variable Coop, and in some specifications their interactions with the prevailing $\alpha$. In the regression of column (1) we add Female only and find that it obtains a significant negative coefficient. When we add also an interaction between Female and $\alpha$, in column (2), however, the sign on Female switches and there is a highly significant negative coefficient on the interaction term. The idea that females contribute less than males that is conveyed by regression (1) thus appears to be mainly attributable to the fact that female subjects contribute more when $\alpha$ is low but are significantly less responsive to increases in this incentive measure. ${ }^{17}$

\section{Insert Table 4 around here}

Column (3)'s specification adds only Coop, which does not obtain a significant coefficient. When both Coop and its interaction with $\alpha$ are entered, in column (4), the Ring-test measure of cooperativeness seems to correctly identify a propensity to contribute to a public good, along with a relative insensitivity to the strength of the individual incentive. Finally, when all four variables are included in column (5), we see that the effects shown in columns (2) and (4) continue to hold but are strengthened in

\footnotetext{
${ }^{17}$ Note that the negative coefficient on the interaction term is still considerably smaller than the positive coefficient on $\alpha$ itself. Hence female subjects are somewhat responsive to incentives, just less so than males are.
} 
both magnitude and significance. Thus, Female and Coop appear to capture individual preference-related characteristics that are predictive of higher contributions and lower responsiveness to monetary incentives but that are rather distinct. ${ }^{18}$ Note finally that all our previous results remain stable after adding the two variables.

\subsubsection{Regression analysis and further tests of voting choices}

When analyzing voting on $\alpha$ in the $\mathbf{Q V}$ and $\mathbf{R V}$ treatments, we consider two factors influencing own earnings and one that might influence the vote by way of social or otherregarding concerns. Assume subject $i$ votes so as to maximize

$$
U_{i}=f\left(y_{i}, \mathbf{S}_{i}\left(\alpha \mid \mathrm{E}_{\mathrm{i}}, Q\right)\right)
$$

where $y_{i}$ is $i$ 's earnings for the period, as given in (1'), and $\boldsymbol{S}_{i}$ reflects $i$ 's social or otherregarding preference for equality and equity and is permitted to vary depending on $i$ 's endowment $E_{i}$ and on whether endowment was earned $(Q=1)$ or randomly assigned $(Q=$ $0)$ ). $\boldsymbol{S}_{i}$ is an individual-specific function which might be predictable on the basis of $i$ 's gender and background characteristics or $i$ 's behavior in other contexts. For simplicity, we rewrite (2) as an additive function of $i$ 's income and $i$ 's social preferences.

$$
E U_{i}=E\left(y_{i}\right)+\mathbf{S}_{i}\left(\alpha \mid \mathrm{E}_{\mathrm{i}}, Q\right)
$$

We focus first on the effects of $\alpha$ on $i$ 's income. Mathematically, the effect of $\alpha$ on $y_{i}$ decomposes into two terms, making

$$
E U_{i}=g\left\{\left(\frac{\partial y_{i}}{\partial \alpha} \mid C_{i}, C_{-i}\right),\left(\frac{\partial y_{i}}{\partial C_{-i}}\right) E\left(\frac{\partial C_{-i}}{\partial \alpha}\right)\right\}+\mathbf{S}_{i}\left(\alpha \mid \mathrm{E}_{\mathrm{i}}, Q\right)
$$

The first argument of $g$ is the marginal effect of $\alpha$ on $y_{i}$ taking the contributions of each subject as given, and the second is the marginal effect of $\alpha$ on $y_{i}$ acting through its effect on the other group members' contributions. ${ }^{19} \partial y_{i} / \partial \alpha \mid C_{i}, C_{-i}$ and $\partial y_{i} / \partial C_{-i}$ are

\footnotetext{
${ }^{18}$ Indeed, the Spearman rank correlation coefficient between Female and Coop is $-0.179(p<0.001)$ for the full sample for which there are valid observations for Coop.

${ }^{19}$ The impact of changing $\alpha$ on $i$ 's income through a change in $i$ 's own contribution is ignored by virtue of the usual envelope argument.
} 
immediately calculable at observed $C_{\text {-i }}$ values using $\left(1^{\prime}\right)^{20}$, while a subject can form expectations of $E\left(\partial C_{-i} / \partial \alpha\right)$ by observing impacts of changing $\alpha$ on group-mates' contributions up to the time of a given vote. ${ }^{21}$ Assuming a first-order condition that can be linearized in the arguments of (2"), we adopt as the core of our estimating equation:

$$
{ }^{v} \alpha_{i t}=b_{0}\left[\left(\frac{4}{3}\right) C_{i}-\left(\frac{2}{3}\right)\left(C_{j}+C_{k}\right)\right]+b_{1}\left\{\frac{2}{3}(1-\alpha) E\left(\partial C_{-i} / \partial \alpha\right)\right\}+b_{2}(\mathbf{Q V})+\varepsilon_{i t}
$$

where ${ }^{v} \alpha_{i t}$ is the value of $\alpha$ for which subject $i$ votes in period $t$. On the right hand side (RHS), the term multiplying coefficient $b_{0}$ is the expression for $\partial y_{i} / \partial \alpha \mid C_{i}, C_{-i}$. To implement the second RHS term, we need an assumption about how subject $i$ forms an expectation of $\partial \mathrm{C}_{-} / \partial \alpha$ in period $t$. We assume that $i$ calculates a weighted average of past observed changes in others' contributions in her group, placing greater weight on more recent changes because she assumes that others' reactions may be evolving with experience, because she remembers more clearly more recent changes, or for some combination of the two reasons. Specifically, we set

$$
E\left(\partial C_{-i} / \partial \alpha\right)=\Delta_{\max }\left\{\left[\sum_{\tau=1}^{t-1}\left(\Delta C_{-i} / \Delta \alpha\right)_{\tau, \tau-1}(1 /(1+d))^{t-\tau}\right] /\left[\sum_{\tau=1}^{t-1} \Delta_{\max }(1 /(1+d))^{t-\tau}\right]\right\}
$$

where $\Delta_{\max }$ is the maximum possible value of $\Delta \mathrm{C}_{\mathrm{i}} / \Delta \alpha, d \geq 0$ is the backward discounting rate for past observations, and the term in curled brackets is thus the weighted average proportion of the maximum possible change in contributions that $i$ has observed. ${ }^{22}$

${ }^{20} \partial y_{i} / \partial \alpha \mid C_{i}, C_{-i}=(4 / 3) C_{i}-(2 / 3) C_{-i}$ and $\partial y_{i} / \partial C_{-i}=2 / 3(1-\alpha)$.

${ }^{21}$ Recall that according to standard theory, $\partial C_{-i} / \partial \alpha=0$ everywhere except at $\alpha=0.25$, where it is infinite. Expectations of realistic $\partial C_{-i} / \partial \alpha$ values, which are neither 0 nor infinite, are therefore based on observed behavior, not on theory.

${ }^{22} \Delta_{\max }=250,200$ and 150 for low, middle and high endowment subjects, respectively, since the smallest possible change in $\alpha$ is 0.1 and the largest possible change in $C$ is 5,10 and 15 for the three endowment types, in the same order. We adopt the ratio form in the curled brackets in (4) so that the backward discounted sum of past $\Delta C_{i} / \Delta \alpha$ observations does not grow larger simply because more past periods are included (with each added term in the numerator, the maximum value of the change in the same period is added to the denominator). To deal with those adjacent periods $\tau$ and $\tau$-1 in which $\alpha$ is unchanged in a given group, we (a) treat $\Delta C_{i} / \Delta \alpha$ as 0 in any period prior to the earliest observed change of $\alpha$ in a group, (b) treat $\Delta C_{-i} / \Delta \alpha$ as 0 in the most recent of a series of adjacent periods without change of $\alpha$, and (c ) for any adjacent periods without change of $\alpha$ for which there are observations of $\Delta C_{i} / \Delta \alpha$ in earlier and later pairs of periods (including a later 0 imposed due to (b)), we set $\Delta C_{i} / \Delta \alpha$ by linear interpolation of those values. 
Equation (3) is estimated inserting values of (4) calculated using alternative values of $d$, and we then select the best-fitting value by means of the Akaike and Schwarz information criteria. The full expression that coefficient $b_{1}$ multiplies includes $(2 / 3)(1-\alpha)$, which is $\partial y_{i} / \partial C_{-i}$ of equation (2"). To simplify the discussion of our estimates, we refer to the purely distributive term multiplied by $b_{0}$ as the "distributive effect" and to the term measuring $\alpha$ 's effect on $i$ 's income through changes in others' contributions - which has coefficient $b_{1}$ - as the "incentive effect." In our regressions, we allow for differences in the incentive effect at different endowment levels by including interactions with low and high endowment dummy variables, but we omit such interactions for the distributive effect because its structure already incorporates contribution terms and is thus in practice highly correlated with endowment.

With respect to the social preference portion of (2")- $\mathbf{S}_{i}\left(\alpha \mid \mathrm{E}_{\mathrm{i}}, Q\right)$-we control for the possibility that subjects view redistribution as less fair when endowments are earned via quiz performance by including a dummy variable for our $\mathbf{Q V}$ treatment, Quiz, as well as two endowment dummy interactions. We also investigate possible social preferences by including in some specifications Female or Female and Coop dummy variables. We include free-standing dummy variables for two endowment levels to check whether endowment levels have effects not captured by the other terms. A time trend is also included, as are group fixed effects. Finally, $\varepsilon_{i t}$ is an error term. Our prediction corresponds to $b_{0}>0, b_{1}>0$ and $b_{2}>0$.

Table 5 displays the results of the regression estimates using best-fitting $d=1.4$ as determined in the simplest specification, that of column (1). That column's result supports our predictions with significant positive coefficients on the distributive and incentive effects, although the latter is effectively zero for middle endowment subjects, considering the interaction term. The quiz (or 'earned endowment') treatment effect is insignificant for high endowment subjects, weakly significant and negative for middle endowment subjects, and highly significant and positive for those with low endowment. Hence, our prediction regarding $b_{2}$ is supported for the latter only. Low endowment as such has a large and significant negative effect on the vote for $\alpha$, while the coefficient on middle endowment is small and quite insignificant after controlling for the other effects, 
indicating no difference with high endowment subjects except via interactions with the incentive and treatment effects. There is a significant positive coefficient on Period, indicating an economically small upward trend.

\section{Insert Table 5 around here}

The results in columns (2) and (3), which add Female and Coop dummies, are qualitatively similar for the other variables except that the incentive effect becomes insignificant for low endowment subjects in column (3), and there is a significant positive effect of Quiz for high in addition to low endowment subjects in specification (3), an additional success for our prediction regarding $b_{2}$. The new results also provide support for the idea that individual preferences matter to voting. In particular, female subjects appear to favor significantly more equal distribution, after controlling for other factors, in specification (2). However, when the Ring Test classification Coop is included, in column (3), only it is significant and negative.

In sum, our regressions based on equation (3) suggest that subjects' votes on the distribution parameter were significantly influenced by its direct effect on their own earnings (distributive effect), while its predicted effect via its influence on others' contributions (incentive effect) is significant for high and possibly low but not middle endowment subjects. Even after controlling for the distributive effect, low endowment subjects favor more redistribution, but their zeal in this regard is significantly reduced when endowments were earned by quiz performance, an indication of respect for earned inequalities. Only middle endowment subjects are - contrary to $\mathrm{Hb} .1$ - more inclined to redistribute when endowments are due to quiz performance. ${ }^{23}$

\footnotetext{
${ }^{23}$ Conceivably, "sour grapes" are at work: some runner-up middle subjects might believe that they came very close and were denied the prized high position by chance and thus unfairly. In contrast, few or no low subjects may doubt that the high and middle ones performed better on the quiz.
} 


\section{Discussion and conclusion}

We introduce a new experimental design to study the struggle between equality, equity and the need for incentives, one of the most important sets of trade-offs in economic life. Our framework can be applied to the general question regarding the tradeoff between equality and incentives that every society has to answer through decisions on taxes and redistribution, but it can, for instance, also be applied to the question of optimal incentives for work teams. Our new design nests the voluntary contribution mechanism in a more variable incentive model and makes incentive settings endogenous. By adding only slightly more complexity to one of the most familiar games in the literature of experimental economics, we get a much richer framework that is able to answer a broader class of questions than the standard public goods game.

Our main findings can be summarized as follows: First, high and low endowment subjects' votes are largely (although not entirely) predictable from self-interest, with the former mostly favoring payment proportionate to contributions and the latter favoring more equal payment.

Second, despite the important role of self-interested behavior, there are significant signs of preferences for both equality and equity. In particular, subjects display greater preference for equality when inequalities are arbitrary than when they are earned by task performance, since low and high endowment subjects are observed to vote for more equality if endowments were not earned. This is clear evidence that subjects distinguish between the concepts of equality and equity when the predictions based on them are not the same. Moreover, female subjects and those scored as more cooperative, based on a Ring-test, contribute more unconditionally, are less responsive to incentives, and show a preference for greater equality in their voting on the division parameter. It is also important that subjects in our experiment select an incentive setting that reduces inequality by $22 \%$, on average, relative to the inequality of their endowments and of a distribution in proportion to inputs. By and large this figure does not seem to be far from the extent of redistribution that we observe in modern industrial capitalist societies (Milanovic, 2000).

Third, there is evidence that low endowment subjects' contributions are influenced by strategic considerations: low endowment subjects contribute more when the marginal 
return is less than one if the division is determined by vote (presumably to signal willingness to cooperate despite low incentive) than when the same division parameters arise exogenously. High endowment subjects influence groups' choices of the division parameter by withholding contributions when it is relatively low, even though contributing the full endowment maximizes their immediate payoff. However, the withholding of contributions by high endowment subjects may be more a response to perceived unfairness than a conscious attempt to influence votes, since there is actually less such behavior in groups with voting.

Finally, subjects respond to the strength of incentives in a roughly continuous fashion, rather than jumping from zero contributions when their marginal return for contributing is below unity to full contributions when it exceeds that threshold, as standard theory would predict.

With respect to the hypotheses laid out in our theoretical predictions section, our results, while partly consistent with conventional predictions Hn.1 and Hn.2, were generally more consistent with behavioral predictions Hb.1 - Hb.3. The main exceptions are Hb.1's prediction regarding voting by middle endowment subjects and $\mathrm{Hb} .2$ 's prediction of more strategic withholding of contributions by high endowment subjects at low $\alpha$ values in voting than in non-voting treatments.

Our setup provides a straightforward way of using the experimental laboratory to study one of the most important questions of economics. The evidence we present shows that self-interest, other-regarding preferences and strategic considerations all play major roles in determining behavior. While subjects vote mainly in line with self-interest, many show dislike of inequality. Consistent with Alesina and Angeletos (2005) and Bénabou and Tirole (2006), the degree of redistribution is sensitive to the perceived fairness of inequalities. We find the richer members of our mini-societies influencing decisions on redistribution by holding back on effort. And the democratic process in our endogenous treatments lead to results broadly in line with what we observe in real societies.

In addition to the macroeconomic implications of our experiment, there are some further lessons to be drawn for the design of actual institutions. One is that continuous rather than dichotomous response to the incentive parameter suggests that organizations considering an element of reward-sharing, for instance to foster helping behaviors among 
workers, can anticipate smaller responses of changes in marginal rewards than standard theory predicts. Another implication, most relevant to cooperatives and other intentionally solidaristic organizations, is that the desires of some team members to reduce inequalities as an end in itself means that maximization of joint utility and of joint money payoffs call for different choices along the spectrum of incentives versus equality.

Because people are fairly mobile among organizations, the macro-political economic implications of our experiment may be even more important than are the micro ones, despite the tiny size of our experimental "societies". Even though our design makes the presence of fairness preferences and incentive considerations more transparent by making the immediate interest of the likely median voters a neutral one, an interesting extension would be to mimic the right-skewedness of real world income distributions by starting with an asymmetric distribution of endowments $-5,8,15$, say, rather than the 5 , 10,15 of the current design - in which case we should expect to see somewhat more redistribution prevail. One suggestion that might be drawn from the deleterious effect of such redistribution on incentives is that a more equal initial distribution of skills and other assets, which can be fostered by education and tax policies, among others, could provide a foundation for a more prosperous society. 


\section{References}

Abowd, John and Michael Bognanno, 1995, "International Differences in Executive and Managerial Compensation," in Richard Freeman and Lawrence Katz, eds., Differences and Changes in Wage Structures. Chicago: University of Chicago Press.

Ackert, Lucy, J. Martinez-Vazquez and M. Rider, 2007, "Social Preferences and Tax Policy Design: Some Experimental Evidence," Economic Inquiry 45: 487-501.

Akerlof, George, 1982, "Labor Contracts as Partial Gift Exchange," Quarterly Journal of Economics 47 (4): 543-569.

Alchian and Demsetz, 1972, "Production, Information costs, and Economic Organization. American Economic Review 62: 777-95.

Alesina, Alberto and George Angeletos, 2005, "Fairness and Redistribution: U.S. versus Europe," American Economic Review 95: 960-80.

Amiel, Yoram, John Creedy and Stan Hurn, 1999, "Measuring Attitudes towards Inequality," Scandinavian Journal of Economics 101: 83-96.

Anderson, Simon P., Jacob K. Goeree and Charles A. Holt, 1998, "A theoretical analysis of altruism and decision error in public goods games," Journal of Public Economics 70: 297-323.

Andreoni, James, 1988, "Why Free Ride? Strategies and Learning in Public Goods Experiments," Journal of Public Economics 37: 291-304.

Andreoni, James, 1989, “Giving with Impure Altruism: Applications to Charity and Ricardian Equivalence," Journal of Political Economy 97: 1447-58.

Andreoni, James, 1990, "Impure Altruism and Donations to Public Goods: A Theory of Warm-Glow Giving,"' Economic Journal 100: 464-77.

Aoki, Masahiko, 1984, The Cooperative Game Theory of the Firm. Oxford: Calrendon Press.

Baker, George, Michael Jensen and Kevin Murphy, 1988, "Compensation and Incentives: Practice Vs. Theory," Journal of Finance 43: 593-616.

Beckman, Steven, John Formby and W. James Smith, 2004, "Efficiency, Equity and Democracy: Experimental Evidence on Okun's Leaky Bucket," in Frank Cowell, 
ed., Inequality, Welfare and Income Distribution: Experimental Approaches. Boston: JAI Press.

Bénabou, Roland, 2000, "Unequal Societies: Income Distribution and the Social Contract," American Economic Review 90: 96-129.

Bénabou, Roland and Jean Tirole, 2006, "Belief in a Just World and Redistributive Politics," Quarterly Journal of Economics 121: 699-746.

Bhargava, Sandeep, 1994, "Profit Sharing and the Financial Performance of Companies:

Evidence from U.K. Panel Data,” Economic Journal 104: 1044-56.

Brosig, Jeannette, 2002, "Identifying Cooperative Behavior: Some Experimental Results in a Prisoner's Dilemma Game," Journal of Economic Behavior and Organization 47: 275-90.

Buckley, Edward and Rachel Croson, 2006, "Income and Wealth Heterogeneity in the Voluntary Provision of Linear Public Goods," Journal of Public Economics 90: 935-55.

Burrows, Paul and Graham Loomes, 1994, "The Impact of Fairness on Bargaining Behavior," Empirical Economics 19: 201-21.

Camerer, Colin and Richard Thaler, 1995, "Anomalies: Ultimatums, Dictators and Manners," Journal of Economic Perspectives 9: 209-19.

Cappelen, Alexander, Erik Sørensen and Bertil Tungodden, 2010, "Responsibility for What? Fairness and Individual Responsibility," European Economic Review 54: 429-441.

Carlsson, Fredrik, Dinky Daruvala and Olof Johansson-Stenman, 2005, "Are People Inequality-Averse, or Just Risk-Averse?" Economica 72: 375-96.

Chan, Kenneth S., Stuart Mestelman, Rob Moir and R. Andrew Muller, 1996, "The Voluntary Provision of Public Goods under Varying Income Distributions," Canadian Journal of Economics 29: 54-9.

Chan, Kenneth S., Stuart Mestelman, Rob Moir and R. Andrew Muller, 1999, "Heterogeneity and the Voluntary Provision of Public Goods," Experimental Economics 2: 5-30.

Charness, Gary and Matthew Rabin, 2002, "Understanding Social Preferences with Simple Tests," Quarterly Journal of Economics 117: 817-69. 
Che, Yeon-Koo and Seung-Weon Yoo, 2001, "Optimal Incentives for Teams," American Economic Review 91: 525-41.

Cherry, Todd L., Stephan Kroll and Jason Shogren, 2005, "The Impact of Endowment Heterogeneity and Origin on Public Good Contributions: Evidence from the Lab," Journal of Economic Behavior and Organization 57: 357-65.

Croson, Rachel, 2007, "Theories of Commitment, Altruism and Reciprocity: Evidence from Linear Public Goods Games,“ Economic Inquiry 45: 199 - 216.

Durante, Ruben and Louis Putterman, 2009, "Preferences for Redistribution and Perception of Fairness: An Experimental Study," Brown University Department of Economics Working Paper 2007-13 (Revised).

Fehr, Ernst and Klaus Schmidt, 1999, "A Theory of Fairness, Competition and Cooperation," Quarterly Journal of Economics 114: 817-68.

Fischbacher, Urs, 2007, "z-Tree: Zurich Toolbox for Ready-Made Economic Experiments," Experimental Economics 10: 171-178.

Fischbacher, Urs and Simon Gächter, 2010, "Social Preferences, Beliefs, and the Dynamics of Free Riding in Public Good Experiments," American Economic Review, 100, 541-556.

Fischbacher, Urs, Simon Gächter and Ernst Fehr, 2001, "Are People Conditionally Cooperative? Evidence from a Public Goods Experiment," Economics Letters, 71, 397-404.

Fong, Christina, 2001, "Social Preferences, Self-Interest and the Demand for Redistribution," Journal of Public Economics 82: 225-46.

Gächter, Simon and Arno Riedl, 2005, "Moral Property Rights in Bargaining with Infeasible Claims," Management Science 51: 249-63.

Galor, Oded and Joseph Zeira, 1993, "Income Distribution and Macroeconomics," Review of Economic Studies 60: 35-52.

Greiner, Ben, 2004, “An Online Recruiting System for Economic Experiments.” in Kurt Kremer, Volker Macho, eds., Forschung und wissenschaftliches Rechnen 2003. GWDG Bericht 63, Goettingen: Ges. Für Wiss. Datenverarbeitung: 79-93. 
Grosse, Stefan, Louis Putterman and Bettina Rockenbach, 2010, "Monitoring in Teams: Using Laboratory Experiments to Study a Theory of the Firm," Journal of the European Economic Association (in press).

Grossman, Hershel, 1995, "Robin Hood and the Redistribution of Property Income," European Journal of Political Economy 11: 399 - 410.

Güth, Werner, Rolf Schmittberger and Bernd Schwarze, 1982, "An Experimental Analysis of Ultimatum Bargaining," Journal of Economic Behavior and Organization 3: 367-88.

Hoffman, Elizabeth and Matthew L. Spitzer, 1985, "Entitlements, Rights, and Fairness: An Experimental Examination of Subjects' Concepts of Distributive Justice," Journal of Legal Studies 14: 259-97.

Holmström, Bengt, 1982, "Moral Hazard in Teams," Bell Journal of Economics 13: 32440.

Holmström, Bengt and Paul Milgrom, 1994, "The Firm as an Incentive System," American Economic Review 84: 972-91.

Irlenbusch, Bernd and Gabriele Ruchala, 2008, "Relative Rewards within Team-Based Compensation," Labor Economics 15: 141-67.

Isaac, R. Marc and James M. Walker, 1988, "Group Size Effects in Public Goods Provision: The Voluntary Contribution Mechanism," Quarterly Journal of Economics 103: 179-99.

Itoh, Hideshi, 1992, "Cooperation in Hierarchical Organizations: An Incentive Perspective," Journal of Law, Economics and Organization 8: 321-45.

Johansson-Stenman, O., F. Carlsson, D. Daruvala, 2002, "Measuring Future Grandparents' Preferences for Equality and Relative Standing," Economic Journal 112: 362-83.

Kruse, Douglas, 1992, "Profit-sharing and Productivity: Microeconomic Evidence from the United States," Economic Journal 102: 24-36.

Lazear, Edward, 1989, "Pay Equality and Industrial Politics," Journal of Political Economy 97: 561-80. 
Ledyard, John O. (1995), "Public Goods: A Survey of Experimental Research," in John Kagel and Alvin Roth, eds., The Handbook of Experimental Economics. Princeton: Princeton University Press.

Lundberg, Shelly and Robert Pollak, 1996, "Bargaining and Distribution in Marriage," Journal of Economic Perspectives 10: 139-58.

Meltzer, Allan H. and Scott F. Richard, 1981, "A Rational Theory of the Size of Government," Journal of Political Economy 89: 814-927.

Milanovic, Branko, 2000, "The Median-Voter Hypothesis, Income Inequality, and Income Redistribution: An Empirical Test with the Required Data," European Journal of Political Economy 6 (3): 367-410.

Offerman, Theo, Joep Sonnemans and Arthur Schram, 1996, "Value Orientations, Expectations and Voluntary Contributions in Public Goods," Economic Journal 106: 817-46.

Okun, Arthur, 1975, Equality and Efficiency: The Big Trade-off. Washington, D.C.: Brookings Institution.

Palfrey, Thomas and Prisbrey, Jeffrey, 1997, "Anomalous Behavior in Public Goods Experiments: How Much and Why?" American Economic Review; 87: 829-46.

Persson, Torsten and Guido Tabellini, 1994, "Is Inequality Harmful for Growth?" American Economic Review 84: 600-21.

Piketty, Thomas, 1995, "Social Mobility and Redistributive Politics," Quarterly Journal of Economics 110: 551-84.

Sadrieh, Abdolkarim and Harrie Verbon, 2006, "Inequality, Cooperation, and Growth: An Experimental Study,” European Economic Review 50: 1197-222.

Schmidt, Ulrich, Christian Seidl and Stefan Traub, 2009, "An Experimental Study on Individual Choice, Social Welfare, and Social Preferences," European Economic Review 53: 385-400.

Selten, Reinhard, 1975, "Re-examination of the Perfectness Concept for Equilibrium Points in Extensive Games," International Journal of Game Theory 4: 25-55.

Sen, Amartya K., 1966, "Labor Allocation in a Cooperative Enterprise," Review of Economic Studies 33: 361-71. 
Sen, Amartya K., 1997, On Economic Inequality. Expanded Edition. Oxford: Oxford University Press.

Shorrocks, Anthony F., 1983, "Ranking Income Distributions," Economica 50: 3-17.

Van Dijk, Frans, Joep Sonnemans and Frans van Winden, 2002, "Social Ties in a Public Good Experiment," Journal of Public Economics 85: 275-99.

Williamson, Oliver, Michael Wachter and Jeffrey Harris, 1975, "Understanding the Employment Relation: The Analysis of Idiosyncratic Exchange," Bell Journal of Economics 6: 250-78.

Zelmer, Jennifer, 2003, "Linear Public Goods Experiments: A Meta-Analysis," Experimental Economics 6: 299-310. 


\section{Figures}

Figure 1: Relative frequency of votes for each value of $\alpha$, by endowment level and treatment
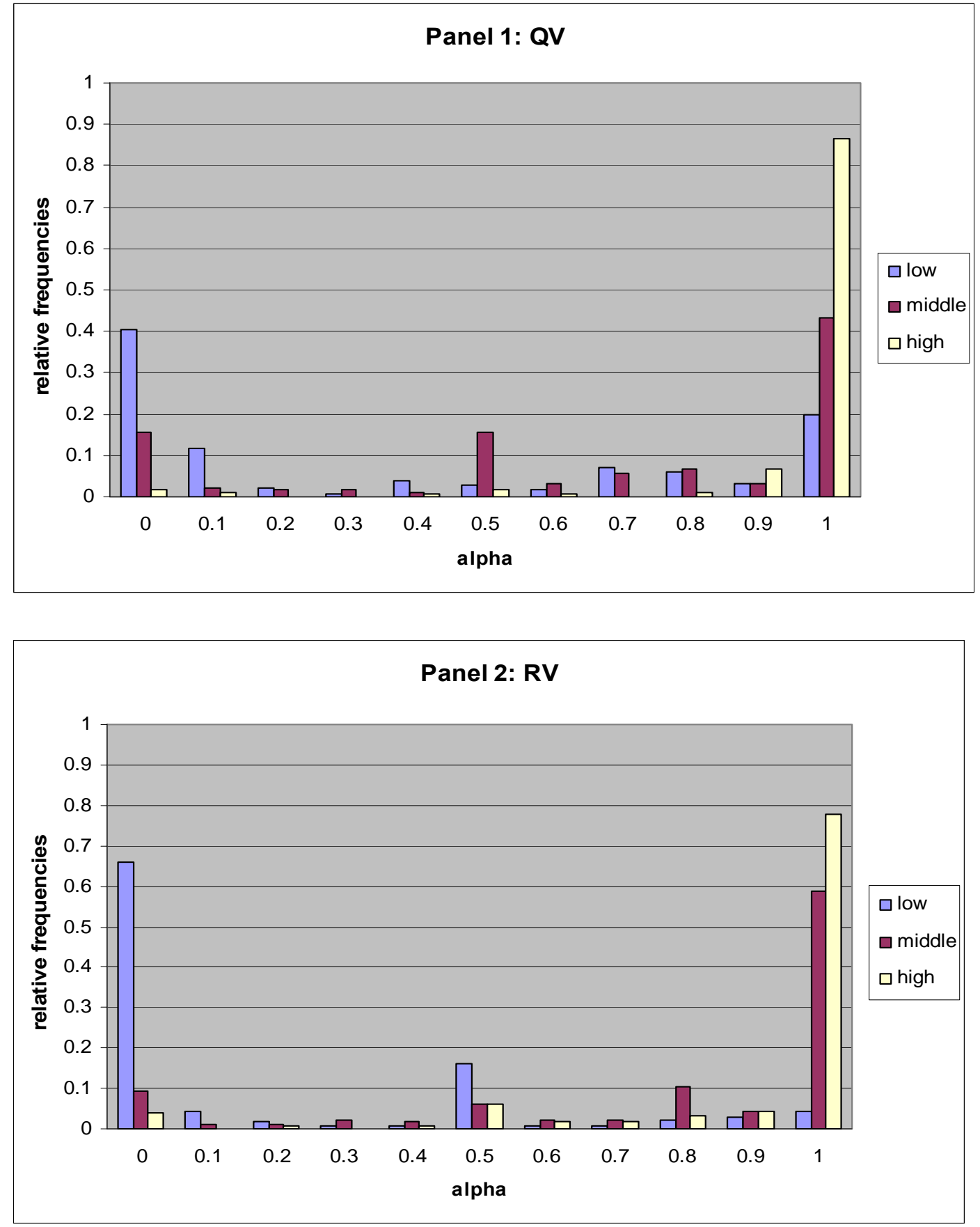


\section{Tables}

Table 1: Treatments, groups and subjects in the experiment

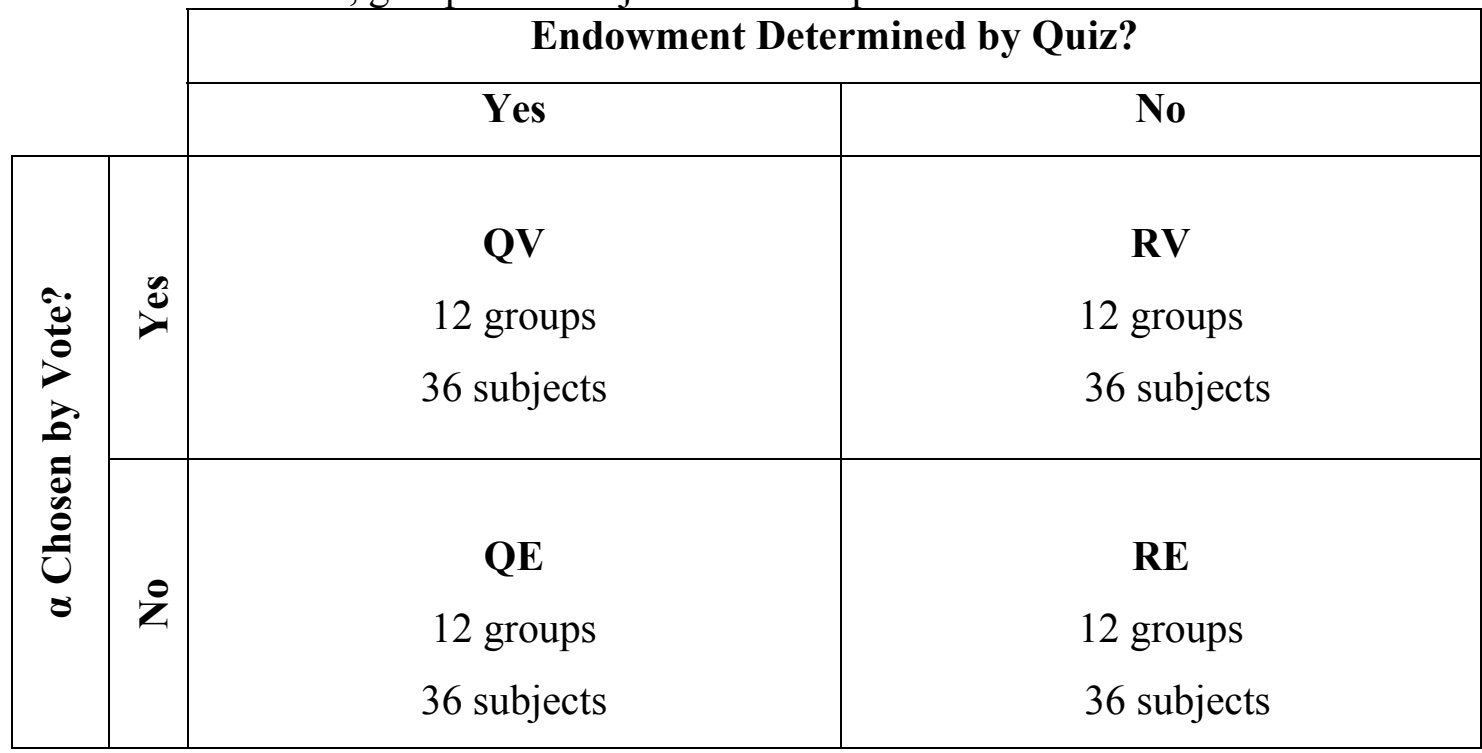


Table 2. Summary statistics on votes and contributions (standard deviations in brackets)

Voted $\alpha \quad$ Exogenous $\alpha$

\begin{tabular}{|c|c|c|c|c|}
\hline \multirow[b]{2}{*}{$\begin{array}{c}\text { Treatment / } \\
\text { Variable }\end{array}$} & & \\
\hline & $\begin{array}{l}\text { Quiz } \\
(\mathbf{Q V})\end{array}$ & $\begin{array}{c}\text { Random } \\
\text { endowment } \\
(\mathbf{R V})\end{array}$ & $\begin{array}{l}\text { Quiz } \\
\text { (QE) }\end{array}$ & $\begin{array}{c}\text { Random } \\
\text { endowment } \\
(\mathbf{R E})\end{array}$ \\
\hline$\alpha$ (votes cast) & $\begin{array}{c}0.669 \\
(0.410)\end{array}$ & $\begin{array}{c}0.625 \\
(0.430)\end{array}$ & $\mathrm{n} / \mathrm{a}$ & $\mathrm{n} / \mathrm{a}$ \\
\hline$\alpha($ votes by low $)$ & $\begin{array}{c}0.387 \\
(0.418)\end{array}$ & $\begin{array}{c}0.187 \\
(0.307)\end{array}$ & $\mathrm{n} / \mathrm{a}$ & $\mathrm{n} / \mathrm{a}$ \\
\hline$\alpha$ (votes by middle) & $\begin{array}{c}0.668 \\
(0.373)\end{array}$ & $\begin{array}{c}0.789 \\
(0.330)\end{array}$ & $\mathrm{n} / \mathrm{a}$ & $\mathrm{n} / \mathrm{a}$ \\
\hline$\alpha$ (votes by high) & $\begin{array}{c}0.951 \\
(0.178)\end{array}$ & $\begin{array}{c}0.900 \\
(0.237)\end{array}$ & $\mathrm{n} / \mathrm{a}$ & $\mathrm{n} / \mathrm{a}$ \\
\hline Median $\alpha$ & $\begin{array}{c}0.792 \\
(0.282)\end{array}$ & $\begin{array}{c}0.768 \\
(0.306)\end{array}$ & $\begin{array}{c}0.792 \\
(0.282)\end{array}$ & $\begin{array}{c}0.768 \\
(0.306)\end{array}$ \\
\hline $\mathrm{C}_{\mathrm{i}} / \mathrm{E}_{\mathrm{i}}$ (all subjects) & $\begin{array}{c}0.863 \\
(0.275)\end{array}$ & $\begin{array}{c}0.870 \\
(0.265)\end{array}$ & $\begin{array}{c}0.828 \\
(0.289)\end{array}$ & $\begin{array}{c}0.884 \\
(0.235)\end{array}$ \\
\hline $\mathrm{C}_{\mathrm{i}} / \mathrm{E}_{\mathrm{i}}$ (low endowment) & $\begin{array}{c}0.858 \\
(0.288)\end{array}$ & $\begin{array}{c}0.883 \\
(0.283)\end{array}$ & $\begin{array}{c}0.854 \\
(0.274)\end{array}$ & $\begin{array}{c}0.879 \\
(0.267)\end{array}$ \\
\hline $\mathrm{C}_{\mathrm{i}} / \mathrm{E}_{\mathrm{i}}$ (middle endowment) & $\begin{array}{c}0.844 \\
(0.270)\end{array}$ & $\begin{array}{c}0.861 \\
(0.265)\end{array}$ & $\begin{array}{c}0.844 \\
(0.273)\end{array}$ & $\begin{array}{c}0.899 \\
(0.209)\end{array}$ \\
\hline $\mathrm{C}_{\mathrm{i}} / \mathrm{E}_{\mathrm{i}}$ (high endowment) & $\begin{array}{c}0.885 \\
(0.267)\end{array}$ & $\begin{array}{c}0.866 \\
(0.248)\end{array}$ & $\begin{array}{c}0.787 \\
(0.315)\end{array}$ & $\begin{array}{c}0.874 \\
(0.227)\end{array}$ \\
\hline $\mathrm{C}_{\mathrm{i}} / \mathrm{E}_{\mathrm{i}}, \alpha<0.25$ & $\begin{array}{c}0.434 \\
(0.398)\end{array}$ & $\begin{array}{c}0.608 \\
(0.436)\end{array}$ & $\begin{array}{c}0.346 \\
(0.283)\end{array}$ & $\begin{array}{c}0.707 \\
(0.364)\end{array}$ \\
\hline $\mathrm{C}_{\mathrm{i}} / \mathrm{E}_{\mathrm{i} \cdot} \cdot 0.3 \leq \alpha \leq 0.6$ & $\begin{array}{c}0.782 \\
(0.294)\end{array}$ & $\begin{array}{c}0.798 \\
(0.288)\end{array}$ & $\begin{array}{c}0.641 \\
(0.309)\end{array}$ & $\begin{array}{c}0.780 \\
(0.285)\end{array}$ \\
\hline $\mathrm{C}_{\mathrm{i}} / \mathrm{E}_{\mathrm{i}} \cdot 0.7 \leq \alpha \leq 1$ & $\begin{array}{c}0.921 \\
(0.203)\end{array}$ & $\begin{array}{c}0.923 \\
(0.197)\end{array}$ & $\begin{array}{c}0.914 \\
(0.212)\end{array}$ & $\begin{array}{c}0.941 \\
(0.154)\end{array}$ \\
\hline
\end{tabular}


Table 3. Determinants of the proportion of endowment contributed I Dependent variable: $C_{i} / E_{i}$

\begin{tabular}{|c|c|c|}
\hline & (1) & (2) \\
\hline$\alpha$ & $\begin{array}{c}0.647 * * * \\
(0.104)\end{array}$ & $\begin{array}{c}0.620 * * * \\
(0.113)\end{array}$ \\
\hline$\alpha^{2}$ & $\begin{array}{c}-0.159 * * \\
(0.076)\end{array}$ & $\begin{array}{l}-0.125 \\
(0.088)\end{array}$ \\
\hline Low endowment & $\begin{array}{c}0.073 \\
(0.054)\end{array}$ & $\begin{array}{c}0.077 \\
(0.051)\end{array}$ \\
\hline Middle endowment & $\begin{array}{c}0.079 \\
(0.051)\end{array}$ & $\begin{array}{c}0.085 \\
(0.049)\end{array}$ \\
\hline$\alpha^{*}$ Low & $\begin{array}{l}-0.073 \\
(0.057)\end{array}$ & $\begin{array}{l}-0.075 \\
(0.053)\end{array}$ \\
\hline$\alpha^{*}$ Middle & $\begin{array}{c}-0.068 \\
(0.054)\end{array}$ & $\begin{array}{c}-0.072 \\
(0.052)\end{array}$ \\
\hline$\left(C_{i} / E_{i}\right)_{(t-1)}$ & $\begin{array}{c}0.259 * * * \\
(0.025)\end{array}$ & $\begin{array}{c}0.199 * * * \\
(0.025)\end{array}$ \\
\hline Period & $\begin{array}{r}-0.0003 \\
(0.001)\end{array}$ & $\begin{array}{c}0.0001 \\
(0.001)\end{array}$ \\
\hline Quiz & $\begin{array}{c}-0.036 * * \\
(0.015)\end{array}$ & $\begin{array}{c}-0.102 * \\
(0.056)\end{array}$ \\
\hline Quiz*Low & $\begin{array}{c}0.007 \\
(0.023)\end{array}$ & $\begin{array}{c}0.007 \\
(0.023)\end{array}$ \\
\hline Quiz*Middle & $\begin{array}{l}-0.001 \\
(0.022)\end{array}$ & $\begin{array}{l}-0.001 \\
(0.021)\end{array}$ \\
\hline Vote & $\begin{array}{l}0.029 * \\
(0.015)\end{array}$ & $\begin{array}{c}0.148 * * * \\
(0.034)\end{array}$ \\
\hline Vote*Low & $\begin{array}{l}-0.025 \\
(0.023)\end{array}$ & $\begin{array}{l}-0.027 \\
(0.023)\end{array}$ \\
\hline Vote ${ }^{*}$ Middle & $\begin{array}{c}-0.045 * * \\
(0.022)\end{array}$ & $\begin{array}{c}-0.048 * * \\
(0.021)\end{array}$ \\
\hline Constant & $\begin{array}{c}0.257 * * * \\
(0.044)\end{array}$ & $\begin{array}{c}0.281 * * * \\
(0.071)\end{array}$ \\
\hline Fixed effects & No & Group \\
\hline No. of observations & 2016 & 2016 \\
\hline R squared & 0.345 & 0.392 \\
\hline Prob. $>$ F & 0.000 & 0.000 \\
\hline
\end{tabular}




\begin{tabular}{|c|c|c|}
\hline & (3) & (4) \\
\hline$\alpha$ & $\begin{array}{c}0.692 * * * \\
(0.112)\end{array}$ & $\begin{array}{c}0.692 * * * \\
(0.112)\end{array}$ \\
\hline$\alpha^{2}$ & $\begin{array}{c}-0.230 * * \\
(0.091)\end{array}$ & $\begin{array}{c}-0.231 * * \\
(0.091)\end{array}$ \\
\hline Low endowment & $\begin{array}{c}0.077 \\
(0.051)\end{array}$ & $\begin{array}{c}0.066 \\
(0.048)\end{array}$ \\
\hline Middle endowment & $\begin{array}{l}0.085 * \\
(0.049)\end{array}$ & $\begin{array}{c}0.060 \\
(0.047)\end{array}$ \\
\hline$\alpha^{*} L o w$ & $\begin{array}{l}-0.075 \\
(0.053)\end{array}$ & $\begin{array}{c}-0.074 \\
(0.053)\end{array}$ \\
\hline$\alpha^{*}$ Middle & $\begin{array}{l}-0.071 \\
(0.051)\end{array}$ & $\begin{array}{c}-0.071 \\
(0.052)\end{array}$ \\
\hline$C_{i} / E_{i}(t-1)$ & $\begin{array}{c}0.199 * * * \\
(0.025)\end{array}$ & $\begin{array}{c}0.202 * * * \\
(0.025)\end{array}$ \\
\hline Period & $\begin{array}{c}0.001 \\
(0.001)\end{array}$ & $\begin{array}{c}0.001 \\
(0.001)\end{array}$ \\
\hline Quiz & $\begin{array}{c}-0.059 * \\
(0.035)\end{array}$ & $\begin{array}{c}-0.056 * \\
(0.032)\end{array}$ \\
\hline Quiz*Low & $\begin{array}{c}0.007 \\
(0.022)\end{array}$ & - \\
\hline Quiz*Middle & $\begin{array}{c}-0.001 \\
(0.021)\end{array}$ & - \\
\hline Vote & $\begin{array}{c}0.110 * * \\
(0.047)\end{array}$ & $\begin{array}{l}0.084 * \\
(0.044)\end{array}$ \\
\hline Vote ${ }^{*}$ Low & $\begin{array}{l}-0.027 \\
(0.023)\end{array}$ & - \\
\hline Vote ${ }^{*}$ Middle & $\begin{array}{c}-0.048 * * \\
(0.021)\end{array}$ & - \\
\hline$\alpha<0.8 * Q u i z$ & $\begin{array}{c}-0.122 * * * \\
(0.027)\end{array}$ & $\begin{array}{c}-0.122 * * * \\
(0.027)\end{array}$ \\
\hline$\alpha<0.8 *$ Vote & $\begin{array}{c}0.033 \\
(0.027)\end{array}$ & $\begin{array}{c}0.033 \\
(0.027)\end{array}$ \\
\hline Constant & $\begin{array}{c}0.326 * * * \\
(0.045)\end{array}$ & $\begin{array}{c}0.335 * * * \\
(0.045)\end{array}$ \\
\hline Fixed effects & Group & Group \\
\hline No. of observations & 2016 & 2016 \\
\hline R squared & 0.402 & 0.400 \\
\hline Prob. $>$ F & 0.000 & 0.000 \\
\hline
\end{tabular}


Table 4. Determinants of the proportion of endowment contributed II

Dependent variable: $C_{i} / E_{i}$

\begin{tabular}{|c|c|c|c|c|c|}
\hline & $(1)$ & $(2)$ & (3) & (4) & (5) \\
\hline \multirow[t]{2}{*}{$\alpha$} & $0.620 * * *$ & $0.667 * * *$ & $0.631 * * *$ & $0.712 * * *$ & $0.785 * * *$ \\
\hline & $(0.113)$ & $(0.117)$ & $(0.123)$ & $(0.120)$ & $(0.120)$ \\
\hline \multirow[t]{2}{*}{$\alpha^{2}$} & -0.125 & -0.121 & -0.144 & $-0.160 *$ & $-0.153 *$ \\
\hline & $(0.088)$ & $(0.087)$ & $(0.094)$ & $(0.093)$ & $(0.091)$ \\
\hline \multirow[t]{2}{*}{ Low endowment } & 0.074 & 0.059 & 0.046 & 0.055 & 0.031 \\
\hline & $(0.051)$ & $(0.051)$ & $(0.056)$ & $(0.056)$ & $(0.054)$ \\
\hline \multirow[t]{2}{*}{ Middle endowment } & $0.088 *$ & 0.075 & 0.008 & 0.009 & -0.001 \\
\hline & $(0.050)$ & $(0.049)$ & $(0.056)$ & $(0.055)$ & $(0.055)$ \\
\hline \multirow[t]{2}{*}{$\alpha^{*} L o w$} & -0.072 & -0.057 & -0.045 & -0.055 & -0.031 \\
\hline & $(0.054)$ & $(0.053)$ & $(0.058)$ & $(0.058)$ & $(0.056)$ \\
\hline \multirow[t]{2}{*}{$\alpha *$ Middle } & -0.074 & -0.060 & 0.004 & 0.005 & 0.012 \\
\hline & $(0.052)$ & $(0.052)$ & $(0.059)$ & $(0.059)$ & $(0.058)$ \\
\hline \multirow[t]{2}{*}{$C_{i} / E_{i}(t-1)$} & $0.197 * * *$ & $0.200 * * *$ & $0.185 * * *$ & $0.184 * * *$ & $0.184 * * *$ \\
\hline & $(0.025)$ & $(0.025)$ & $(0.028)$ & $(0.028)$ & $(0.028)$ \\
\hline \multirow[t]{2}{*}{ Period } & 0.000 & 0.000 & -0.000 & -0.000 & -0.000 \\
\hline & $(0.001)$ & $(0.001)$ & $(0.001)$ & $(0.001)$ & $(0.001)$ \\
\hline \multirow[t]{2}{*}{ Quiz dummy } & $0.142 * * *$ & $0.141 * * *$ & 0.042 & 0.026 & 0.040 \\
\hline & $(0.051)$ & $(0.051)$ & $(0.100)$ & $(0.098)$ & $(0.100)$ \\
\hline \multirow[t]{2}{*}{ Quiz *Low } & 0.011 & 0.015 & -0.013 & -0.016 & -0.010 \\
\hline & $(0.023)$ & $(0.023)$ & $(0.026)$ & $(0.026)$ & $(0.026)$ \\
\hline \multirow[t]{2}{*}{ Quiz*Middle } & 0.003 & 0.004 & 0.009 & 0.013 & 0.020 \\
\hline & $(0.021)$ & $(0.021)$ & $(0.025)$ & $(0.024)$ & $(0.025)$ \\
\hline \multirow[t]{2}{*}{ Vote } & $-0.135 * *$ & $-0.153 * * *$ & -0.025 & -0.023 & -0.059 \\
\hline & $(0.054)$ & $(0.057)$ & $(0.085)$ & $(0.084)$ & $(0.086)$ \\
\hline \multirow[t]{2}{*}{ Vote ${ }^{*}$ Low } & -0.022 & -0.015 & -0.017 & -0.012 & -0.001 \\
\hline & $(0.023)$ & $(0.023)$ & $(0.026)$ & $(0.026)$ & $(0.026)$ \\
\hline \multirow[t]{2}{*}{ Vote ${ }^{*}$ Middle } & $-0.050 * *$ & $-0.049 * *$ & $-0.053 * *$ & $-0.058 * *$ & $-0.062 * *$ \\
\hline & $(0.021)$ & $(0.021)$ & $(0.024)$ & $(0.024)$ & $(0.025)$ \\
\hline \multirow[t]{2}{*}{ Female } & $-0.023 * *$ & $0.073 *$ & - & - & $0.135 * * *$ \\
\hline & $(0.011)$ & $(0.042)$ & & & $(0.044)$ \\
\hline \multirow[t]{2}{*}{$\alpha^{*}$ Female } & - & $-0.124 * * *$ & - & - & $-0.186 * * *$ \\
\hline & & $(0.047)$ & & & $(0.050)$ \\
\hline \multirow[t]{2}{*}{ Coop } & - & - & 0.019 & $0.123 * * *$ & $0.146 * * *$ \\
\hline & & & $(0.012)$ & $(0.047)$ & $(0.046)$ \\
\hline \multirow[t]{2}{*}{$\alpha^{*}$ Coop } & - & - & - & $-0.134 * * *$ & $-0.168 * * *$ \\
\hline & & & & $(0.052)$ & $(0.051)$ \\
\hline \multirow[t]{2}{*}{ Constant } & $0.441 * * *$ & $0.422 * * *$ & $0.315 * * *$ & $0.265 * * *$ & $0.207 * * *$ \\
\hline & $(0.059)$ & $(0.061)$ & $(0.074)$ & $(0.072)$ & $(0.075)$ \\
\hline $\mathrm{N}$ & 2016 & 2016 & 1680 & 1680 & 1680 \\
\hline $\mathrm{R}$ squared & 0.394 & 0.398 & 0.409 & 0.414 & 0.424 \\
\hline Prob. $>\mathrm{F}$ & 0.000 & 0.000 & 0.000 & 0.000 & 0.000 \\
\hline
\end{tabular}

OLS regressions with group fixed effects. Robust standard errors in brackets. ${ }^{*}, * * * *$ denotes significance at the $10 \%, 5 \%, 1 \%$ level respectively. 
Table 5. Determinants of the vote for $\alpha$

OLS regressions with group fixed effects. Dependent variable: $\alpha$

\begin{tabular}{|c|c|c|c|}
\hline & (1) & (2) & (3) \\
\hline Distributive effect $\left(\partial y_{i} / \partial \alpha\right)$ & $\begin{array}{c}0.008 * * * \\
(0.003)\end{array}$ & $\begin{array}{c}0.007 * * * \\
(0.0026)\end{array}$ & $\begin{array}{c}0.010 * * * \\
(0.003)\end{array}$ \\
\hline Incentive effect & $\begin{array}{c}0.0003 * * * \\
(0.0001)\end{array}$ & $\begin{array}{c}0.0003 * * * \\
(0.0001)\end{array}$ & $\begin{array}{c}0.0003 * * * \\
(0.0001)\end{array}$ \\
\hline Incentive_low & $\begin{array}{c}-0.0002 * * \\
(0.0001)\end{array}$ & $\begin{array}{c}-0.00018 * \\
(0.0001)\end{array}$ & $\begin{array}{c}-0.0002 * * * \\
(0.0001)\end{array}$ \\
\hline Incentive_middle & $\begin{array}{c}-0.0003 * * * \\
(0.0001)\end{array}$ & $\begin{array}{c}-0.0003 * * * \\
(0.0001)\end{array}$ & $\begin{array}{c}-0.0003 * * * \\
(0.0001)\end{array}$ \\
\hline Quiz & $\begin{array}{c}0.070 \\
(0.073)\end{array}$ & $\begin{array}{c}0.012 \\
(0.071)\end{array}$ & $\begin{array}{c}0.286 * * * \\
(0.076)\end{array}$ \\
\hline Quiz_low & $\begin{array}{c}0.203 * * * \\
(0.047)\end{array}$ & $\begin{array}{c}0.241 * * * \\
(0.047)\end{array}$ & $\begin{array}{c}0.250 * * * \\
(0.047)\end{array}$ \\
\hline Quiz_middle & $\begin{array}{c}-0.100 * \\
(0.051)\end{array}$ & $\begin{array}{l}-0.075 \\
(0.052)\end{array}$ & $\begin{array}{c}-0.267 * * * \\
(0.059)\end{array}$ \\
\hline Low & $\begin{array}{c}-0.588 * * * \\
(0.057)\end{array}$ & $\begin{array}{c}-0.604 * * * \\
(0.056)\end{array}$ & $\begin{array}{c}-0.614 * * * \\
(0.057)\end{array}$ \\
\hline Middle & $\begin{array}{l}-0.071 \\
(0.044)\end{array}$ & $\begin{array}{c}-0.094 * * \\
(0.044)\end{array}$ & $\begin{array}{l}0.099 * \\
(0.051)\end{array}$ \\
\hline Period & $\begin{array}{l}0.005 * \\
(0.003)\end{array}$ & $\begin{array}{l}0.0056 * \\
(0.0029)\end{array}$ & $\begin{array}{c}0.003 \\
(0.003)\end{array}$ \\
\hline Female & - & $\begin{array}{c}-0.086 * * * \\
(0.028)\end{array}$ & $\begin{array}{l}-0.0003 \\
(0.030)\end{array}$ \\
\hline Coop & - & - & $\begin{array}{c}-0.066 * * \\
(0.030)\end{array}$ \\
\hline Constant & $\begin{array}{c}0.466 * * * \\
(0.087)\end{array}$ & $\begin{array}{c}0.578 * * * \\
(0.090)\end{array}$ & $\begin{array}{c}0.892 * * * \\
(0.053)\end{array}$ \\
\hline $\mathrm{R}^{2}$ & 0.491 & 0.498 & 0.561 \\
\hline $\mathrm{N}$ & 855 & 855 & 737 \\
\hline $\mathrm{p}$ [incentive + inc_low $=0]$ & 0.061 & 0.078 & 0.394 \\
\hline $\mathrm{p}[$ incentive + inc_middle $=0$ ] & 0.355 & 0.547 & 0.770 \\
\hline $\mathrm{p}$ [quiz+quiz_low=0] & 0.001 & 0.001 & 0.000 \\
\hline $\mathrm{p}$ [quiz+quiz_middle $=0$ ] & 0.691 & 0.385 & 0.740 \\
\hline
\end{tabular}




\section{Appendix A: Additional results}

Table A.1. Votes for $\alpha$ by endowment

\begin{tabular}{|ll|r|r|r|r|}
\hline & & \multicolumn{3}{|c|}{ Endowment } & Total \\
\cline { 2 - 6 } & & 5 & 10 & 15 & \\
\hline $\boldsymbol{\alpha}$ & 0.0 & 192 & 45 & 10 & 247 \\
& 0.1 & 29 & 6 & 2 & 37 \\
& 0.2 & 7 & 5 & 1 & 13 \\
& 0.3 & 2 & 7 & 0 & 9 \\
& 0.4 & 8 & 5 & 2 & 15 \\
& 0.5 & 34 & 39 & 14 & 87 \\
& 0.6 & 4 & 10 & 4 & 18 \\
& 0.7 & 14 & 14 & 3 & 31 \\
& 0.8 & 15 & 31 & 8 & 54 \\
& 0.9 & 11 & 14 & 20 & 45 \\
& 1.0 & 44 & 184 & 296 & 524 \\
Mean & & .287 & .729 & .925 & .647 \\
\hline Total & & 360 & 360 & 360 & 1080 \\
\hline
\end{tabular}

Figure A.1

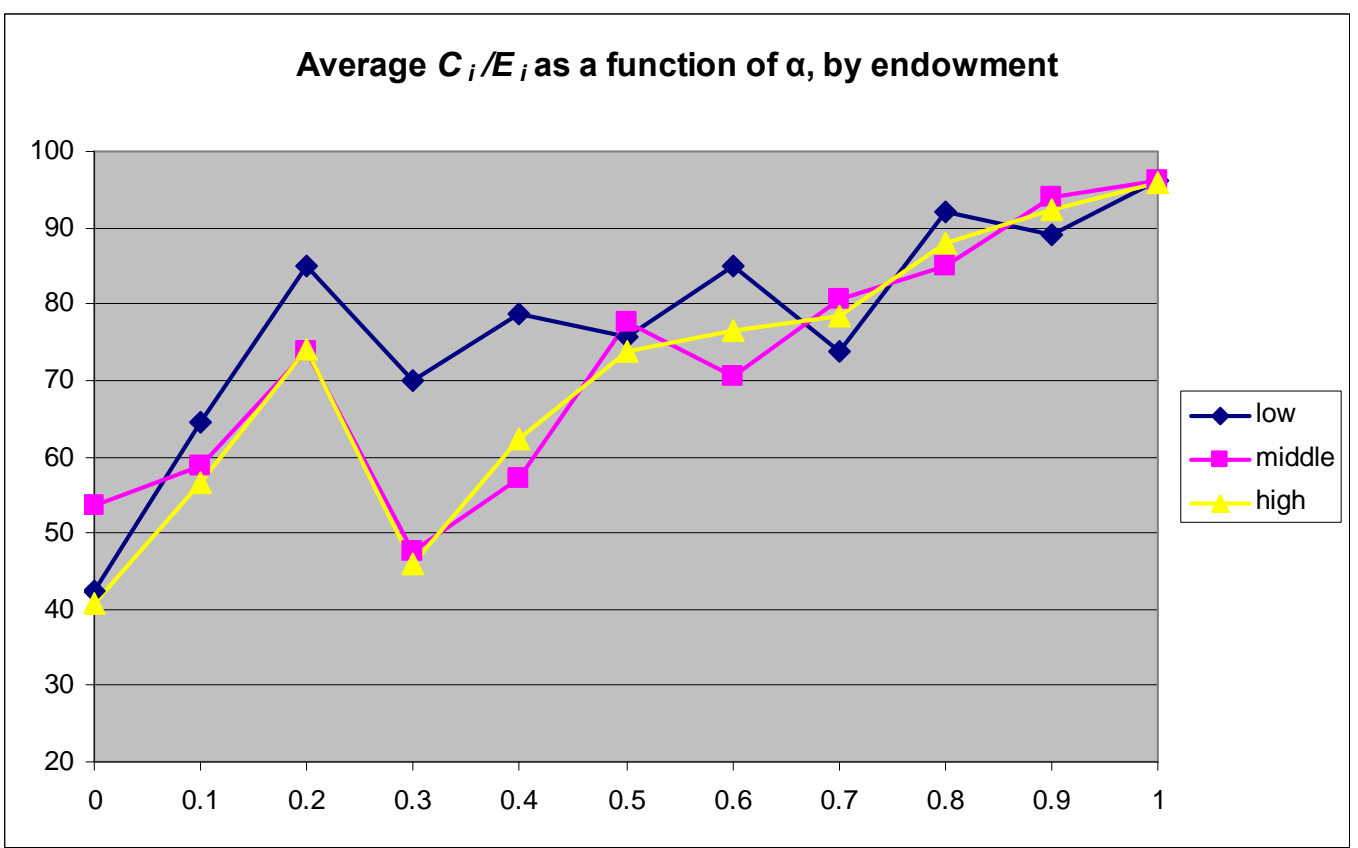




\section{Appendix B: 2SLS/Instrumental variable estimations}

We estimate two-stage least squares models where the value of $\alpha$ in the equation for contributions is predicted by a first-stage regression in which the incentive and distributive effect variables serve as instruments. The main difficulty here is that about half of contribution decisions were made by subjects who had not voted for the value of $\alpha$ that determines their incentive, so including first-stage regressions resembling those in Table 5 is inappropriate for such subjects. A feasible albeit imperfect solution is to estimate 2SLS regressions using only observations of individuals who had voted for the median $\alpha$ in the period in question. ${ }^{24}$ This turns out to be $57 \%$ of all observations, owing to the substantial number of cases in which two or even three group members selected the same $\alpha$. Even so, with observations from the RE and QE treatments (in which $\alpha$ is exogenous) also excluded, our 2SLS estimates are based on far fewer observations than are those of Table 3 (461 versus 2016, or less than 23\%). Any comparison between the contribution regressions discussed in the text and our 2nd stage IV estimates must accordingly be done with caution.

We show three sets of 2SLS regressions that vary with respect to the inclusion or not in the 1 st stage regression of two sets of interaction terms, those between endowment dummy variables and the incentive effect, and those between the same dummies and Quiz. In the new 1st stage regressions, corresponding roughly to the ones shown in Table 5 , the positive and highly significant coefficient on the distributive effect is confirmed, and the effect of Quiz is positive and significant, with specification (3) suggesting that this is especially attributable to the reactions of low endowment subjects. The coefficients on the incentive effect are insignificant except in the no interaction specification, and there is a marginally significant coefficient for the interaction with the low endowment dummy in specification (3). In both cases, the incentive variable has the "wrong" sign.

\footnotetext{
${ }^{24}$ Another conceivable approach would be to include both the $\alpha$ that a given subject voted for, treated as endogenous, and the median $\alpha$ that prevails for the group, treated as exogenous, in the 2nd-stage regressions. But this is infeasible because of the very high correlation between self-voted and median $\alpha$, which is even identical for many observations.
} 
The result seems unsurprising in view of the facts that the predicted incentive effect also failed to hold for middle endowment subjects in Table 5 and that it is middle subjects who account for the bulk of the median voter observations used in this exercise. The Female and Coop dummies are omitted since neither is significant when included. Because these results are equivalent to OLS estimates for the subsample who vote for median $\alpha$ in a given period, differences with Table 5 must be attributed to sample selection (including the aforementioned oversampling of middle subjects), not the 2SLS setting.

It is in the 2nd stage regressions for contributions that differences attributable to the endogeneity of $\alpha$ could potentially appear. Table A.3 shows three versions of the regression which differ only with respect to the 1 st stage variants used to predict $\alpha$, these being the three regressions of Table A.2, with the same order maintained. Because the square of the predicted $\alpha$, the endowment dummies, and all interaction terms involving those dummies turn out to be insignificant, they are dropped from these specifications. The Hansen J-statistics reported at the bottom of the table indicate that the instruments included in the 1 st stage regressions pass the over-identification tests comfortably. ${ }^{25}$ However, the Wu-Hausman tests of weak instruments return F-statistics having $p$-values of about 0.7 , far too high to reject the hypothesis that $\alpha$ is after all exogenous. The predicted $\alpha$ variable obtains highly significant positive coefficients, further allaying any concern that the effect of this parameter on contributions found in previous regressions was due to endogeneity bias. Interestingly, the coefficients on Quiz, which are negative and significant at the 5\% level in Table 3, are positive and significant at the $10 \%$ level in its 2SLS counterparts. However, when we estimate an OLS version of the same contributions regression shown in Table A.3 for the same subset of observations, it turns out that Quiz has a significant positive coefficient in it as well, so that the difference is again attributable to the difference in sample, not to failure to account for the endogeneity of $\alpha$.

\footnotetext{
${ }^{25}$ Comparing Tables A.2 and A.3 shows that in the first equation system, only the distributive and incentive effect variables serve as instruments, while in the second and third equations there are additional interaction terms included in the first but not second stages and therefore also playing the role of instruments.
} 
Table A.2. Determinants of the vote for $\alpha$ (2SLS)

Dependent variable: $\alpha$

\begin{tabular}{|c|c|c|c|}
\hline & (1) & (2) & (3) \\
\hline Distributive effect $\partial y_{i} / \partial \alpha$ & $\begin{array}{c}0.013 * * * \\
(0.002)\end{array}$ & $\begin{array}{c}0.013 * * * \\
(0.002)\end{array}$ & $\begin{array}{c}0.017 * * * \\
(0.003)\end{array}$ \\
\hline Incentive effect & $\begin{array}{c}-0.0001 * * \\
(0.00004)\end{array}$ & $\begin{array}{c}0.0001 \\
(0.0001)\end{array}$ & $\begin{array}{c}0.0001 \\
(0.0001)\end{array}$ \\
\hline Incentive*Low & - & $\begin{array}{l}-0.0002 \\
(0.0001)\end{array}$ & $\begin{array}{c}-0.0002 * \\
(0.0001)\end{array}$ \\
\hline Incentive*Middle & - & $\begin{array}{l}-0.0002 \\
(0.0001)\end{array}$ & $\begin{array}{l}-0.0001 \\
(0.0001)\end{array}$ \\
\hline$C_{i} / E_{i}(t-1)$ & $\begin{array}{l}-0.021 \\
(0.068)\end{array}$ & $\begin{array}{c}-0.011 \\
(0.069)\end{array}$ & $\begin{array}{c}-0.062 \\
(0.077)\end{array}$ \\
\hline Quiz & $\begin{array}{c}0.093 * * * \\
(0.029)\end{array}$ & $\begin{array}{c}0.093 * * * \\
(0.029)\end{array}$ & $\begin{array}{l}0.055 * \\
(0.032)\end{array}$ \\
\hline Quiz*Low & - & - & $\begin{array}{c}0.164 * * \\
(0.080)\end{array}$ \\
\hline Quiz $*$ Middle & - & - & $\begin{array}{c}0.008 \\
(0.046)\end{array}$ \\
\hline Period & $\begin{array}{c}0.011 * * * \\
(0.004)\end{array}$ & $\begin{array}{c}0.011 * * * \\
(0.004)\end{array}$ & $\begin{array}{c}0.011 * * * \\
(0.004)\end{array}$ \\
\hline Constant & $\begin{array}{c}0.669 * * * \\
(0.070)\end{array}$ & $\begin{array}{c}0.660 * * * \\
(0.072)\end{array}$ & $\begin{array}{c}0.697 * * * \\
(0.076)\end{array}$ \\
\hline No. of observations & 461 & 461 & 461 \\
\hline R squared & 0.146 & 0.149 & 0.162 \\
\hline Prob. $>$ F & 0.000 & 0.000 & 0.000 \\
\hline
\end{tabular}


Table A.3. Determinants for the proportion of endowment contributed (2SLS)

Dependent variable: $C_{i} / E_{i}$

\begin{tabular}{lccc}
\hline & $\mathbf{( 1 )}$ & $\mathbf{( 2 )}$ & $\mathbf{( 3 )}$ \\
\hline$\alpha$ & $0.423^{* * *}$ & $0.424^{* * *}$ & $0.412 * * *$ \\
& $(0.109)$ & $(0.107)$ & $(0.108)$ \\
$C_{i} / E_{i}(t-1)$ & $0.167^{* * *}$ & $0.167 * * *$ & $0.168 * * *$ \\
& $(0.053)$ & $(0.053)$ & $(0.053)$ \\
Quiz & $0.036^{*}$ & $0.036^{*}$ & $0.037 *$ \\
& $(0.021)$ & $(0.021)$ & $(0.021)$ \\
Period & -0.003 & -0.003 & -0.003 \\
& $(0.003)$ & $(0.003)$ & $(0.003)$ \\
Constant & $0.414 * * *$ & $0.414 * * *$ & $0.420 * * *$ \\
& $(0.087)$ & $(0.087)$ & $(0.084)$ \\
\hline No. of observations & 461 & 461 & 461 \\
R squared & 0.305 & 0.305 & 0.307 \\
Hansen J statistic (overid. test) & 0.869 & 1.167 & 3.317 \\
Chi-sq(1) P-value & 0.351 & 0.761 & 0.651 \\
Wu-Hausman F statistic & 0.180 & 0.200 & 0.107 \\
(endogeneity test) & 0.671 & 0.655 & 0.744 \\
F (1, 455) P-value & & & \\
\hline
\end{tabular}

Instrumented: $\alpha$

Coefficient robust standard errors are given in brackets. $*, * *, * * *$ denote significance at the $10 \%, 5 \%$ and $1 \%$ level respectively. 


\section{Appendix C: Instructions for treatment $\mathbf{Q V}^{26}$}

Welcome to an experiment on decision-making. Thank you for participating! During the experiment you will be asked to make decisions and so will the other participants. Your decisions, as well as the decisions of the other participants, will determine your monetary payoff according to the rules that will be explained shortly.

As is standard in such experiments, communication of any kind with other participants is prohibited. If you violate this rule, you will be excluded from the experiment. If you have any questions during the experiment, please raise your hand and one of the experimenters will come to assist you.

The experiment is computerized and will last for approximately two hours. Decisions will be made on your screen. All your decisions and answers to questions remain confidential and anonymous. We will use the identification tag that you have received on entering the room only to identify you when we pay you your income after the experiment.

The experiment will consist of two parts. You will receive instructions on the relevant parts in turn. We will read the instructions aloud and, then, give time for you to ask questions. Please do not hesitate to ask if anything is unclear. Decisions in the two parts of the experiment are completely independent.

Your income in the experiment will be in "tokens." At the end of the experiment, tokens will be converted into euro at an exchange rate which is specified in the respective part.

\section{Part I}

In Part I, all persons in the room will be randomly matched into pairs of two. Nobody will find out neither during nor after the experiment with whom he or she was connected. You will have to make 24 choices between two options, called Option A and Option B. Every option allocates a positive or negative number of tokens to your account and a positive or negative amount of tokens to the other person's account. This other person answers exactly the same questions. Your total income from Part I depends on your decision and the decision of the other person in your pair.

Example:

\begin{tabular}{|c|c|c|}
\hline & Option A & Option B \\
\hline Your payoff & 10.00 & 7.00 \\
\hline Other's payoff & -5.00 & 4.00 \\
\hline
\end{tabular}

\footnotetext{
${ }^{26}$ The instructions for the other treatments are analogous.
} 
If you choose option A, you will receive 10 tokens and the other person will be deducted 5 tokens. If the other person in your pair chooses option A too, then you will also receive a deduction of 5 tokens. In total you would have earned 5 tokens (10 tokens from your choice minus 5 tokens from the choice of the other person).

In case you choose option B and the other person chooses option A, you will receive 2 tokens $(7$ tokens from your own choice minus 5 tokens from the choice of the other person in your pair). The other person would have earned 14 tokens (10 tokens +4 tokens).

Your total income from Part I will be determined as follows: Looking at your decisions, the values for "Your payoff" will be summed up. Looking at the person you are connected with, the values for "Other's payoff" will be summed up. The sum of both sums determines your payoff and will be exchanged into euros according to the following exchange rate: $\mathbf{3}$ tokens $=\mathbf{1}$ euro. This exchange rate is only valid for Part I.

You do not get any information on single decision of the person you are paired with, but you will be informed about the sum of payoffs.

Please raise your hand if you have any questions. We will come to your seat to answer them.

\section{Part II ${ }^{27}$}

The tokens you earn in Part II will be exchanged into euros at the end of the experiment according to the following exchange rate: 10 tokens $=1$ euro.

All participants will be divided in groups of three members. You will not learn the identity of the other participants in your group.

\section{At the beginning of Part II}

At the outset you will be asked to answer 20 trivia questions. For each question, we will provide four answers, but only one of them is correct. The endowment that you will receive in each of the subsequent periods in Part II depends on the number of questions you answer correctly. Specifically, the group member within your group with the most correct answers will receive the highest endowment; the group member within your group with the second-most correct answers will receive the second-highest endowment and so on. Equal numbers of correct answers will be resolved by a random draw of the computer. Thus, there is always a strict ranking of endowments within your three-person group.

The distribution of endowments within your group will be:

\footnotetext{
${ }^{27}$ Handed out after completion of Part I.
} 


\begin{tabular}{cc}
$\begin{array}{c}\text { Rank (according to } \\
\text { correct answers) }\end{array}$ & $\begin{array}{c}\text { Endowment each period } \\
\text { of Part II }\end{array}$ \\
\hline $\mathbf{1}$ & 15 tokens \\
$\mathbf{2}$ & 10 tokens \\
$\mathbf{3}$ & 5 tokens \\
\hline \hline
\end{tabular}

The rank will also be your group member number.

\section{The basic decision situation}

You will learn later exactly how the experiment is conducted. We first introduce you to the basic decision situation. You will find control questions at the end of the description of the decision situation that help you to get a better understanding.

As you know you will be a member of a group consisting of 3 people. In each period each group member has to decide on the allocation of his or her endowment. You can either invest your endowment into your private account or you can contribute them fully or partially to a project. Each token you do not contribute to the project will automatically remain in your private account.

\section{Your income from the private account each period}

You will earn one token for each token you put into your private account. For example, if you put 15 tokens into your private account, your income in this period will amount to exactly 15 tokens out of your private account. If you put 2 tokens into your private account, your income from this account will be 2 tokens for that period. No one except you earns something from your private account.

\section{Your income from the project each period}

Your income from the project depends on three things: (1) your contribution to the project, (2) the combined contribution to the project by all group members, and (3) a proportion $x$, between 0 and 1, which determines the weight placed on (1) versus (2).

If $x=1$, only your own contribution to the project affects your project income; in particular, your project income is then $2 \cdot \mathrm{c}_{\mathrm{i}}$, where $\mathrm{c}_{\mathrm{i}}$ is your contribution.

If $x=0$, only the combined contribution affects your project income; in particular, your project income is then $(2 \cdot \mathrm{C}) / 3$, where $\mathrm{C}$ is the total contribution to the project by all members of your group, yourself included.

If $x$ is more than 0 but less than one, some weight is placed both on $c_{i}$ (or more specifically, on $2 \cdot \mathrm{c}_{\mathrm{i}}$ ) and on $\mathrm{C}($ that is, on $(2 / 3) \cdot \mathrm{C})$.

Generalizing, what you earn is $(1-x) \cdot \frac{2 \cdot C}{3}+x \cdot 2 \cdot c_{i}$.

\section{Your total income each period}

Your total income is the sum of your income from your private account and that from the project: 
Income from your private account (= endowment - contribution to the project)

+ Income from the project

$=$ Sum of income each period

Or, mathematically:

Income $=\left(e_{i}-\right.$ own contributions $)+(1-x) \cdot \frac{2}{3} \cdot($ all contributions in your group $)$

$+x \cdot 2 \cdot($ your contribution $)$

where $\mathrm{e}_{\mathrm{i}}$ denotes your endowment.

Remember: $x$ is the weight placed on your contribution, $(1-x)$ is the weight placed on the total contributions within your group.

\section{Control questions}

Please answer the following control questions. They will help you to gain an understanding of the calculation of your income, which varies with your decision about how you distribute your tokens. Please answer all the questions and write down your calculations. After that, please enter your answers on the screen.

For the first set of questions, assume that $\mathrm{x}=1$ and that you are the second-ranked member of your group, i.e., your endowment is 10 tokens.

1. Assume that none of the three group members (including you) contributes anything to the project.

What will your total income in tokens be? Your income

What will group Member 1's total income in tokens be?

What will group Member 3's total income in tokens be?

2. You contribute 10 tokens to the project. The other members of the group contribute 13 , respectively 4 tokens to the project.

What will your total income be? Your income

What will group Member 1's total income in tokens be?

What will group Member 3's total income in tokens be?

3. The other two members contribute a total of 5 tokens to the project.

a) What will your total income be, if you - in addition to the 10 tokens contribute 0 tokens to the project? Your Income

b) What will your total income be, if you - in addition to the $\overline{10 \text { tokens }}-$ contribute 5 tokens to the project? Your Income

c) What will your total income be, if you - in addition to the 10 tokens contribute 10 tokens to the project? Your Income

4. Assume that you contribute 5 tokens to the project.

a) What is your total income if the other group members - in addition to your 5 tokens - contribute another 3 tokens to the project? Your Income 
b) What is your total income if the other group members - in addition to your 5 tokens - contribute another 10 tokens to the project? Your Income

c) What is your income if the other group members - in addition to your 5 tokens - contribute another 20 tokens to the project? Your Income

For the second set of questions, assume that $\mathrm{x}=0$ and that you are again the secondranked member of your group, i.e., your endowment is 10 tokens.

5. Assume that none of the three group members (including you) contributes anything to the project.

What will your total income in tokens be? Your income

What will group Member 1's total income in tokens be?

What will group Member 3's total income in tokens be?

6. You contribute 10 tokens to the project. The other members of the group contribute 13 , respectively 4 tokens to the project.

What will your total income be? Your income

What will group Member 1's total income in tokens be?

What will group Member 3's total income in tokens be?

7. The other two members contribute a total of 10 tokens to the project.

a) What will your total income be, if you - in addition to the 10 tokens contribute 2 tokens to the project? Your Income

b) What will your total income be, if you - in addition to the 10 tokens contribute 5 tokens to the project? Your Income

c) What will your total income be, if you - in addition to the 10 tokens contribute 8 tokens to the project? Your Income

8. Assume that you contribute 5 tokens to the project.

a) What is your total income if the other group members - in addition to your 5 tokens - contribute another 4 tokens to the project? Your Income

b) What is your total income if the other group members - in addition to your 5 tokens - contribute another 10 tokens to the project? Your Income

c) What is your income if the other group members - in addition to your 5 tokens - contribute another 19 tokens to the project? Your Income

For the third set of questions, assume that $\mathrm{x}=0.5$ and that you are again the secondranked member of your group, i.e., your endowment is 10 tokens.

9. Assume that none of the three group members (including you) contributes anything to the project.

What will your total income in tokens be? Your income What will group Member 1's total income in tokens be? What will group Member 3's total income in tokens be? 
10. You contribute 10 tokens to the project. The other members of the group contribute 13 , respectively 4 tokens to the project.

What will your total income be? Your income

What will group Member 1's total income in tokens be?

What will group Member 3's total income in tokens be?

11. The other two members contribute a total of 10 tokens to the project.

a) What will your total income be, if you - in addition to the 10 tokens contribute 2 tokens to the project? Your Income

b) What will your total income be, if you - in addition to the $\overline{10 \text { tokens }}-$ contribute 5 tokens to the project? Your Income

c) What will your total income be, if you - in addition to the $\overline{10 \text { tokens }}-$ contribute 8 tokens to the project? Your Income

12. Assume that you contribute 5 tokens to the project.

a) What is your total income if the other group members - in addition to your 5 tokens - contribute another 4 tokens to the project? Your Income

b) What is your total income if the other group members - in addition to your 5 tokens - contribute another 10 tokens to the project? Your Income

c) What is your income if the other group members - in addition to your 5 tokens - contribute another 19 tokens to the project? Your Income

\section{The Procedure}

Each period in Part II consists of two phases, and there are a total of 15 such periods in Part II. After the trivia questions, you will learn your rank within your group (equal to your group member number) and your endowment. You will receive this endowment at the beginning of each period, and your rank will not change from period to period.

\section{Phase 1 - choice of $x$ :}

Your group can choose the preferred $\mathrm{x}$. You can choose from the following values of $\mathrm{x}$ : $0,0.1,0.2,0.3,0.4,0.5,0.6,0.7,0.8,0.9$ and 1. Each group member will be asked to propose his or her preferred $\mathrm{x}$. The median of these three proposals within your group will then be implemented and be valid for this period.

Suppose the three proposals within your group are: $0.1,0.2$ and 0.3 . The median proposal to be implemented would be 0.2 .

Suppose the three proposals within your group are: $0.9,1$ and 1 . The median proposal to be implemented would be 1 .

Suppose the three proposals within your group are: 0.5, 0.6 and 0.6. The median proposal to be implemented would be 0.6 .

At the end of Phase 1 you will be informed about the relevant median proposal.

\section{Phase 2 - contribution decision:}


Each member of the group has to decide on how much of his or her endowment to contribute to the project. The rest of the individual endowment will be automatically invested into the private account.

Your income for this period will be determined in the following way:

\section{Reminder}

Your total income is the sum of your income from your private account and that from the project:

Income from your private account (= endowment - contribution to the project)

$$
+ \text { Income from the project }
$$

$=$ Sum of income each period

Or, mathematically:

$$
\text { Income }=\left(e_{i}-c_{i}\right)+(1-x) \cdot \frac{2 \cdot C}{3}+2 \cdot x \cdot c_{i}
$$

At the end of each period, you will be informed about all individual contributions within your group (you will be able to link them to the Member numbers) and your period income in tokens as well as the individual period income in tokens of the other two members.

Each of the 15 periods will be identical and will follow the protocol described above. You will be staying in the same group for the 15 periods, i.e., the two other group members will remain unchanged over Part II of the experiment.

\section{The End}

Your total income over the 15 periods will be converted to euro (at the exchange rate 10 tokens $=1 €$ ) and privately be paid to you at the end of the experiment. It will be added to the amount that you earned from Part I of the experiment.

After Part II, we ask you to fill in a questionnaire. Please answer the questions frankly and seriously because they are very important for our research. Thereafter, the experiment ends. There will be no other parts or repetitions.

Please raise your hand if you have any questions. We will come to your place to answer them privately. 


\section{Appendix D: Ring-Test}

The social orientation questionnaire consists of 24 choices (see Table A.4) between two own-other payoff allocations (the "decomposed game") in constant, anonymous pairs. Each allocation assigns a given amount of experimental money to the subject herself, called own payoff $x$, and a certain amount of points to the matched player, called other payoff $y$. It was common knowledge that every subject received the same questionnaire. During the questionnaire players did not receive any feedback about the other player's choices in order to avoid strategic considerations. The payoff allocations were constructed such that $r^{2}=15^{2}=x^{2}+y^{2}$ holds. Hence, each allocation can be represented as a vector in a Cartesian plane which lies on a circle with radius $r$ centred at the origin.

The payoff allocations are paired such that each choice consists of two adjacent vectors. If one assumes that a - yet unknown - motivational vector $\vec{M}$ exists, a subject will choose that allocation (vector) which is closer to $\vec{M}$. Based on a series of choices, therefore, it is possible to determine a subject's "social motivation" with respect to weighing own payoffs $(x)$ versus others payoffs $(y)$ by adding up $x$ and $y$ separately across all choices and calculating the angle $\theta_{M}$ of the resulting vector $\vec{M}$. By means of this angle subjects' motivation can be classified as belonging to one of the following eight categories: individualism, altruism, cooperation, competition, martyrdom, masochism, sadomasochism, and aggression.

In addition, the length of the motivational vector serves as a measure of consistency, i.e., whether the choices are taken such that the subject has always chosen that vector which is closest to the motivational vector. If a subject chooses consistently throughout the 24 choices, the length of the resulting vector would be 30 . Random choice would result in a vector of zero length.

In order to incentivize the procedure, subjects' total payoffs from the series of choices were determined by the sum of choices made by the subject herself and by the choices of the paired player. 
Table A.4. Ring-test - own-other payoff allocations

\begin{tabular}{|c|c|c|c|c|}
\hline \multirow[b]{2}{*}{ Question number } & \multicolumn{2}{|c|}{ Option A } & \multicolumn{2}{|c|}{ Option B } \\
\hline & self $(x)$ & other (y) & $\operatorname{self}(x)$ & other (y) \\
\hline 1 & 15 & 0 & 14.5 & -3.9 \\
\hline 2 & 13 & 7.5 & 14.5 & 3.9 \\
\hline 3 & 7.5 & -13 & 3.9 & -14.5 \\
\hline 4 & -13 & -7.5 & -14.5 & -3.9 \\
\hline 5 & -7.5 & 13 & -3.9 & 14.5 \\
\hline 6 & -10.6 & -10.6 & -13 & -7.5 \\
\hline 7 & 3.9 & 14.5 & 7.5 & 13 \\
\hline 8 & -14.5 & -3.9 & -15 & 0 \\
\hline 9 & 10.6 & 10.6 & 13 & 7.5 \\
\hline 10 & 14.5 & -3.9 & 13 & -7.5 \\
\hline 11 & 3.9 & -14.5 & 0 & -15 \\
\hline 12 & 14.5 & 3.9 & 15 & 0 \\
\hline 13 & 7.5 & 13 & 10.6 & 10.6 \\
\hline 14 & -14.5 & 3.9 & -13 & 7.5 \\
\hline 15 & 0 & -15 & -3.9 & -14.5 \\
\hline 16 & -10.6 & 10.6 & -7.5 & 13 \\
\hline 17 & -3.9 & -14.5 & -7.5 & -13 \\
\hline 18 & 13 & -7.5 & 10.6 & -10.6 \\
\hline 19 & 0 & 15 & 3.9 & 14.5 \\
\hline 20 & -15 & 0 & -14.5 & 3.9 \\
\hline 21 & -7.5 & -13 & -10.6 & -10.6 \\
\hline 22 & -13 & 7.5 & -10.6 & 10.6 \\
\hline 23 & -3.9 & 14.5 & 0 & 15 \\
\hline 24 & 10.6 & -10.6 & 7.5 & -13 \\
\hline
\end{tabular}

The classification of the subjects was accomplished by means of the angle of the motivational vector $\vec{M}$ (based on the vectors defining the basic social motivation; see Figure C1) Subjects with an angle $\theta_{M}$ between $0^{\circ}$ and $22.5^{\circ}$ or $337.5^{\circ}$ and $0^{\circ}$ were classified as individualistic, subjects with an angle between $22.5^{\circ}$ and $67.5^{\circ}$ as cooperative. Further angles were: altruist (between $67.5^{\circ}$ and $112.5^{\circ}$ ), martyrdom (between $112.5^{\circ}$ and $157.5^{\circ}$ ), masochism (between $157.5^{\circ}$ and $202.5^{\circ}$ ), sadomasochism 
(between $202.5^{\circ}$ and $247.5^{\circ}$ ), aggression (between $247.5^{\circ}$ and $292.5^{\circ}$ ), and competitive (between $292.5^{\circ}$ and $337.5^{\circ}$ ), but they are very rarely observed in practice. To avoid examining subjects who made relatively inconsistent choices we included in the analysis only those subjects with a vector length of 15 (out of the maximal length of 30 ).

Figure A.1. Vectors defining the basic social motivation

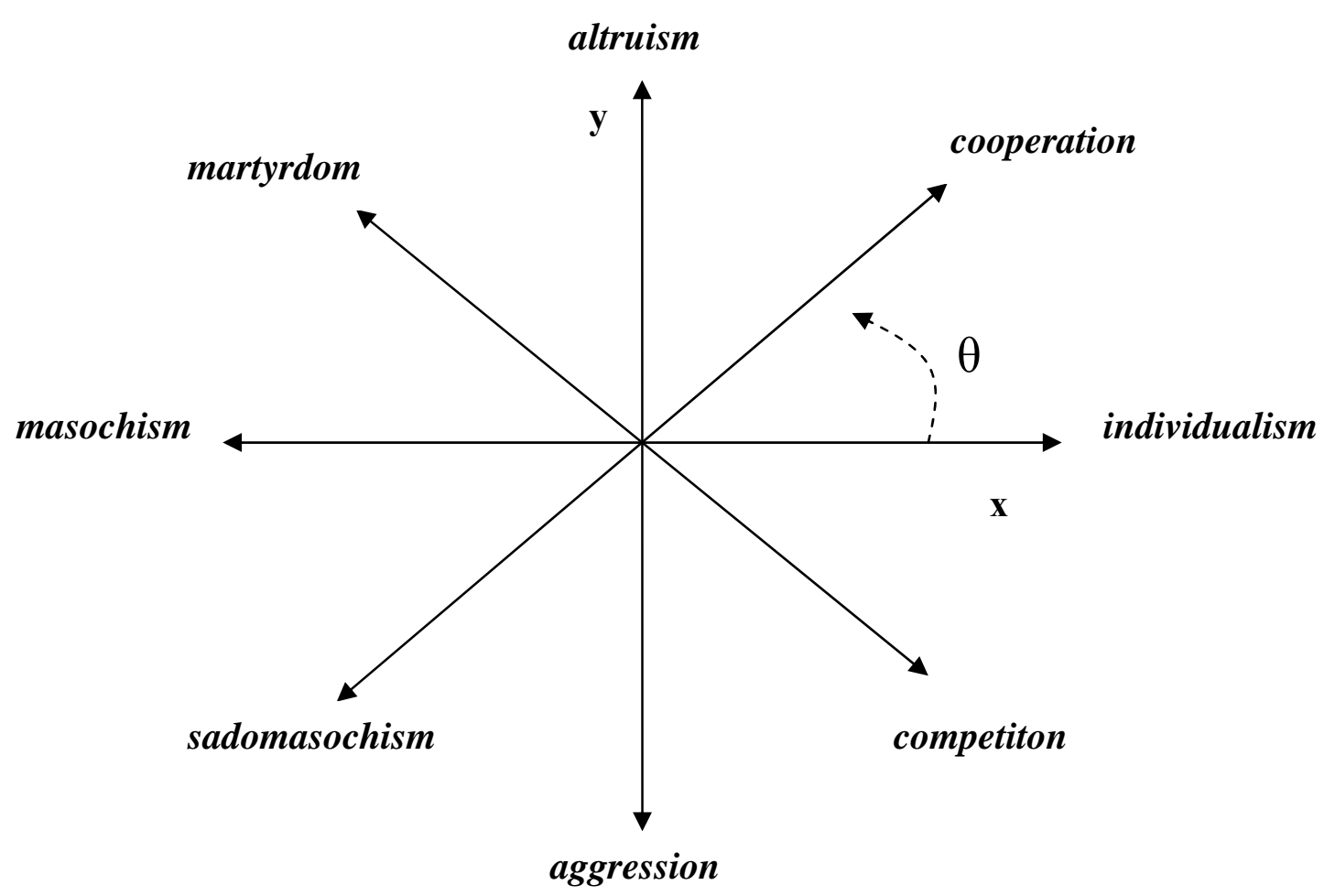

